\title{
Soglasniški sklopi v cerkljanskem narečju
}

\author{
Karmen Kenda-Jež
}

Prispevek prinaša popis (vzglasnih, izglasnih in medsamoglasniških) soglasniških sklopov v osrednjecerkljanskem narečju. Inventar sklopov je primerjan s tistim iz slovenskega knjižnega jezika, kakor je predstavljen v obravnavah Jožeta Toporišiča in Tatjane Srebot-Rejec.

\section{Consonant Clusters in the Cerkno Dialect}

This article presents the inventory of initial, final, and intervocalic consonant clusters in the central Cerkno dialect. The cluster inventory is comparable to that in Standard Slovenian as presented in the works of Jože Toporišič, and Tatjana Srebot-Rejec.

0 Sinhroni soglasniški sestav cerkljanskega narečja je bil obravnavan že nekajkrat (Logar 1996a: 32; 1996b: 411; Rigler 1981: 67; Kenda-Jež 1999: 209). ${ }^{1}$ Prikazi se v glavnem med sabo ujemajo - razlikujejo se le po (ne)upoštevanju alofonov [3], [̌̌], [g] -, odstopa pa prva Logarjeva predstavitev, ki navaja posebne fonetične uresničitve zvenečih $b$ in $d$ v izglasju $(-f,-b)$ in menjavanje $w-b / b \mathrm{v}$ medsamoglasniškem položaju, za kar pa v osrednji cerkljanščini v do sedaj zbranem gradivu, tudi v zapisih Tineta Logarja za Slovenski lingvistični atlas (SLA), ni potrditve. Jan Baudouin de Courtenay (1884: 390) je v svoji razpravi o cerkljanskem narečju ${ }^{2}$ izglasna $b / d$ zapisoval kot aspirirana $p^{\prime}, t$, , kar so povzemali tudi poznejši opisi narečja do preloma tisočletja (Ramovš 1935: 91; 1936: 130; Logar 1993: 119; Toporišič 1992: 13). Na sledove teh aspiriranih glasov je pri zbiranju gradiva za SLA leta 1951 Tine Logar še naletel v Šebreljah, v gradivu za Cerkno pa jih je zabeležil le v novem izglasju (po samoglasniški redukciji). ${ }^{3}$ Poznejši zapisi s tega področja aspiracije ne izkazujejo več, ${ }^{4}$ torej ne gre več za sinhrono lastnost osrednjecerkljanskih govorov.

1 Prispevek je predelan odlomek poglavja Glasoslovje iz doktorskega dela Cerkljansko narečje: Teoretični model dialektološkega raziskovanja na zgledu besedišča in glasoslovja (Ljubljana 2002), ki je nastalo pod mentorstvom akad. Tineta Logarja.

2 Oprta je na gradivo za govora krajev Cerkno in Otalež.

3 Podrobneje o tem v Kenda-Jež 1998: 150.

4 Npr. za Cerkno Riglerjev zapis za Slovanski lingvistični atlas (OLA) iz leta 1966, zapis Slavice Bric-Makuc za SLA iz leta 1982, zapis govora kraja Otalež (Tomaž Pavšič, 1960) in objavljena narečna besedila s tega področja v Logar 1993: 45-49. 
0.1 Soglasniški sestav osrednjecerkljanskega narečja se od knjižnega loči po odsotnosti drsnika $v$ in priporniškem $\gamma$ namesto knjižnega $g$ :

\begin{tabular}{lllll}
\multicolumn{2}{l}{ Zvočniki } & & & \\
$\mathrm{w}$ & {$[\mathrm{u}]$} & & $\mathrm{m}$ & {$[\mathrm{m}]$} \\
& 1 & $\mathrm{r}$ & $\mathrm{n}$ & {$[\mathrm{y}]$} \\
$\mathrm{j}^{5}$ & & & &
\end{tabular}

\begin{tabular}{|c|c|c|}
\hline & očnik & \\
\hline & b & $\mathrm{f}$ \\
\hline & $\mathrm{d}$ & \\
\hline & {$[3]^{6}$} & s \\
\hline & [̌̌ & šs \\
\hline & [g] & $\mathrm{x}$ \\
\hline
\end{tabular}

0.2.1 Na razvrstitev soglasnikov $\mathrm{v}$ cerkljanskem narečju so vplivale narečne razvojne posebnosti, kot so (1) drugotno mehčanje mehkonebnikov $|k|,|\gamma|,|x|$, ki je zvišalo pogostnost pojavljanja $/ \check{c} /,|\breve{z} /,| \breve{s} / ;(2)$ prehod ponaglasnega $w i(\leftarrow i, \check{e})>j$,

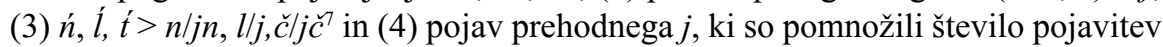
fonema $/ j /$; (5) nastop protetičnega $w$ - pred $a$ - $(\leftarrow o$, v izposojenkah tudi $\leftarrow a, e)$; (6) prehod $\check{s} c ̌ s$, (7) asimilacija (-)wu: > u: ('du:jčk 'dvojček', 'tu:j 'tvoj') in (8) različne olajšave težko izgovorljivih soglasniških sklopov pri omejenem naboru leksemov (npr. $m n>m, d n>n ; m n>u n, p x>u x, k t>x t$ ipd.; prim. Kenda-Jež 1999: 221-224), kar je privedlo do zmanjšanja števila soglasnikov v sklopu ali spremenilo njegovo fonetično podobo.

0.2.2 Pravila o razvrščanju soglasnikov se nekoliko razlikujejo od tistih v knjižnem jeziku. Zveneči nezvočnik se $\mathrm{v}$ govorni verigi na koncu besede pred sledečim zvočnikom ne ohranja le pri pravih predlogih, ampak v vseh primerih. V tem položaju je mogoč tudi zveneč izgovor nezvenečega nezvočnika (Kenda-Jež

5 V slovenskih dialektoloških zapisih se je sredi osemdesetih let začel uveljavljati poseben način zapisovanja glasu /j/ oz. njegovih različic po načelih, ki so se izoblikovala ob prvih objavah narečnega gradiva $v$ zvezkih OLA in po katerih se $\langle i$ 〉 uporablja samo pri zapisu diftongov, $v$ vseh drugih primerih pa drugačna fonetična vrednost $/ j /$ ni posebej označena. Tak način zapisovanja je ohranjen tudi v tem prispevku, ker cerkljanščina spada med narečja s slušno težko zaznavno razliko med [j] in [i], kar je v vzorčnih Fonoloških opisih (1981) navadno izraženo s formulo »/j/ ima ne pred vokalom varianto [i] , razen tega že sam [j] $n i$ izrazito spirantičen« (poud. K. K.-J., za Cerkno prim. Rigler 1981: 68).

6 Primeri novejših izposojenk iz italijanščine, v katerih se 3 pojavlja tudi pred samoglasnikom ( $3 u^{\prime}$ keta), so osamljeni.

7 In sicer $\dot{n}>j n$ v položaju za samoglasnikom in $\dot{l}>j l, \dot{t}>j \check{c}$ v položaju za naglašenim e-jevskim samoglasnikom (Kenda-Jež 1999: 221-223.) 
1999: 211). V cerkljanščini so nosilci zloga lahko tudi zvočniki [m],[m], [ño, [y], [1], v vzglasju za pavzo tudi $/ \mathrm{r} / .^{8}$

0.3 Obravnava vzglasnih, izglasnih in medsamoglasniških sklopov je oprta na fond vseh izpričanih pregibnih oblik ter glasoslovnih različic iz oblikovnih razdelkov slovarskih gesel v nastajajočem slovarju osrednjecerkljanskega narečja (ok. 6600 gesel) ter na ok. 250 strani transkribiranih narečnih besedil iz krajev Cerkno (C), Zakojca (Z), Podlanišče (Po), Gorje (G), Ravne (Ra), Šebrelje (̌̌), Planina (PI), Lazec (L) in Straža (S). Oblikovni razdelek je nastal s popolnim in paberkovalnim izpisom iz zvočnega gradiva (pribl. 80 ur posnetkov) vodenih pogovorov z informanti starejše generacije v letih 1985-1995. Gre za zapise na podlagi slušnega vtisa, brez dodatnih eksperimentalnofonetičnih raziskav, ki jih danes zaradi slabe kakovosti posnetkov žal ni mogoče naknadno opraviti. Objava tega gradiva se zato zdi smiselna kot izhodišče za morebitno novo, primerjalno raziskavo, ki bi lahko že spremljala tudi jezikovnorazvojne težnje, obenem pa eksperimentalnofonetično preverila sporne zapise, zlasti pri zaporedjih $t / d+$ zlitnik (Toporišič 1978: 42; Brozović 2006: 68), pri katerih lahko pričakujemo nastop t. i. »dolgih zlitnikov«, a so bili na podlagi slušnega vtisa in v skladu $\mathrm{z}$ zapisovalsko tradicijo zapisovani kot zaporedje dveh soglasnikov (prim. npr. Rigler 1966: s'latče 'sladke'). Približno 16.000 besednih oblik verjetno ni dovolj za zajetje vseh redkeje pojavljajočih se soglasniških sklopov - zato preštevalna statistika ni smiselna -, zadostuje pa za prikaz nabora najpogostnejših. Ker do sedaj poleg razprave Martine Orožen (1990), ki tipološko obravnava problematiko soglasniških sklopov v slovenskih narečjih z jezikovnorazvojnega vidika, obstaja en sam sinhroni opis začetnih in končnih soglasniških sklopov v kakem slovenskem narečju, in sicer za podjunščino v Zdovčevem (1972: 45-51) opisu govora jugovzhodne Podjune na Koroškem (Die Mundart des Südöstlichen Jauntales in Kärnten), mednarečna kontrastivna razčlemba sklopov ni bila mogoča. Zato je bil inventar sklopov primerjan s tistim iz knjižnega jezika, kakor je prikazan v razpravi Jožeta Toporišiča (1978) Soglasniški sklopi slovenskega knjižnega jezika, magistrski nalogi Soglasniški sklopi v slovenščini in kontrastivna analiza angleških in slovenskih soglasniških sklopov (1975a) in iz nje nastali razpravi Tatjane Srebot-Rejec (1975b) Začetni in končni soglasniški sklopi v slovenskem knjižnem jeziku. ${ }^{9}$

8 Drugače Rigler (1981: 68, 72).

9 Merila za sestavo izhodiščne zbirke besedja za popis soglasniških sklopov se v različnih slovenskih prikazih med seboj razlikujejo. Medtem ko npr. Tatjana Srebot-Rejec (1975: 290) iz SP 1962 in SSKJ 1 izloča neknjižne, arhaične, redke, napolcitatne, kratične besede in onomatopeje, pa tudi »izrazito učen[e] in tehničn[e] besede«, Unuk (2003: 5) gradivo SSKJ upošteva v celoti, merila za izpis enot iz SP 1962 pa niso posebej predstavljena. Da je pri obravnavi soglasniških sklopov v knjižnem jeziku treba upoštevati zvrstno označenost besedja, pričajo zavajajoči primeri besed iz neknjižnih zvrsti, ki so v knjižni jezik sprejete v nesistemski poknjiženi obliki. Prim. npr. Unukovo (2003: 64, op. 6) trditev, da se v knjižnem jeziku »[z]a končne štiričlenske nize [...] pojavi samo en primer«, ki se sklicuje na besedo dirndl (2003: 247, 254), sistemsko dirndel -dla. 
0.4 V cerkljanskem narečju lahko $\mathrm{v}$ vseh položajih stojijo soglasniški sklopi z največ štirimi soglasniki. Na meji dveh besednih enot je bilo mogoče najti največ petdelne medbesedne soglasniške sklope, vendar so ti redkejši ('ku:jst spad'ra:se 'tako preraste'), tri- ali štiridelni sklopi pa so v govorjenju običajni. Število možnih členov $\mathrm{v}$ verigi je torej nekoliko manjše kot $\mathrm{v}$ knjižnem jeziku (pet $\mathrm{v}$ vzglasju, štiri v izglasju in sredi besede, do osem na meji med besedama), $\mathrm{v}$ glavnem na račun zvočniškega zaporedja $n+j, l+j(<\dot{l}, \dot{n})$. Na drugačno število in razvrstitev posameznih soglasniških sklopov v knjižnem jeziku in cerkljanskem narečju poleg močne samoglasniške redukcije in že omenjenih narečnih razvojev vpliva tudi deloma drugačna glasovna podoba prevzetih besed. V nasprotju s knjižnim jezikom je $\mathrm{v}$ narečju tako $\mathrm{v}$ vzglasju kot $\mathrm{v}$ izglasju mogoč tudi sklop iz dveh enakih soglasnikov (s'si:kane, $z^{\prime} z i d a u$, 'xatt). Po razvrstitvi se od ustreznih v knjižnem jeziku najbolj razlikujejo izglasni sklopi dveh nezvočnikov, čeprav je število ugotovljenih povezav v obeh skorajda enako. Številčno razmerje $(29: 13)$ med tovrstnimi sklopi v cerkljanskem in podjunskem narečju (Zdovc 1972: 50) pa kaže, da bi to lahko bil tudi eden od merljivih kazalcev stopnje samoglasniške redukcije v slovenskih narečjih.

Soglasniški sklopi ${ }^{10}$ so popisani glede na položaj v besedi in glede na število členov ${ }^{11}$ dvočlenski sklopi pa so opremljeni s preglednicami možnih povezav. Zveze soglasnikov z zlogotvornimi zvočniki, ki so za narečje značilne in zlasti številne $\mathrm{v}$ ponaglasni in izglasni legi, so prikazane kot neuresničljivi soglasniški sklopi v drugi točki vsakokratnega prikaza oz. v posebnem razdelku, razvrstitev soglasniških prvin ob nosilcu zloga pa je primerjana s tisto ob samoglasniku.

\section{$1 \quad$ Vzglasni sklopi}

Na začetku besede lahko stoji soglasniški sklop z dvema, tremi ali štirimi soglasniki.

\subsection{Dvodelni sklopi}

\subsubsection{Z + Z}

(1) Kot prva sestavina sklopa $\mathrm{v}$ domačih besedah nastopata samo $m$ in $u$, pa še pri slednjem je varianta $u \mathrm{v}$ vzglasju običajnejša. Zaradi prehoda $\dot{n} / \hat{l}>n / l \mathrm{v}$ položaju pred samoglasnikom $\mathrm{v}$ gradivu razen izjemoma, $\mathrm{v}$ novejših sposo-

${ }^{10} \mathrm{~V}$ slovenskem jezikoslovju uveljavljeno poimenovanje (prim. Jurgec 2003: 155) se v razpravi nanaša na zaporedje soglasnikov v govorni verigi ne glede na morfemsko ali zlogovno mejo, torej ne glede na to, ali gre za »prave« ali »neprave« sklope.

${ }^{11}$ Zemljepisna omejenost posameznih oblik je označena s krajevnim označevalnikom pred besedo (C, Z, Pd, B, G, Ra, Š, L, S). Krajšave za slovnične podatke: I R D T M O = sklon; ed dv $\mathrm{mn}=$ število, 123 = oseba, $\mathrm{m}$ ž s = spol, sed. = sedanjik, ned. = nedoločnik, vel. = velelnik, del. $-l=$ deležnik na $-l$. Drugo: $Z=$ zvočnik, $N=$ nezvočnik, $\approx=$ dvojnica; $\mathrm{HI}=$ hišno ime, $\mathrm{T}=$ toponim. $\mathrm{V}$ preglednicah: $+=$ obstoj sklopa, $\oplus=$ medsamoglasniški sklop. Enačaju sledi poknjiženi zapis besede. 
jenkah, ni sklopa $n j$, po vokalni redukciji nastalo zaporedje $l+Z$ (tudi $l j$ ) pa ne tvori vzglasnega sklopa ( $l$ postane zlogotvoren).

m $\quad \mathbf{m l}-m l a ' t i c ̌, m l a ' d u r, m^{\prime} l i: k a, m^{\prime} l e ̣: u, \mathbf{m r}-m^{\prime} r a s, m^{\prime} r o w a=$ mrva 'drobtina', mj - m'ja:uka (sed. 3ed; edini primer)

u un $-u$ ula'ča:n = vlačan 'prožen, žilav', úla:n 'lani', úlliẹšt = uleči, u

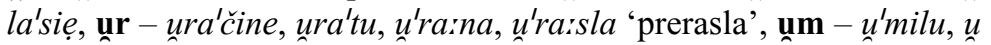
ma're:ijn 'v omari', unn - ư'na:jn, u ne'dẹ:jle, unj - unjja:meš, u Je'liệ $\mathrm{T}$ n $\quad \mathbf{n j}-n^{\prime} j o ̣: k i$ (edini primer, novejša izposoja)

(2) $\quad l$ in $r$ sta v položaju pred drugim zvočnikom zlogotvorna. $r$ je le položajna različica $/ \partial+r /$ na začetku besede za pavzo, v govorni verigi za samoglasnikom pa izgubi zlogotvornost (Kenda-Jež 1999: 210).

$1 \quad$ lj $-l_{\circ}^{\prime} j a: k=$ lijak, low $-l_{0}^{\prime}$ wica $=$ levica

r $\quad \mathbf{r j}-r_{0}^{\prime} j a: w a$

\subsection{2 $\mathrm{N}+\mathrm{N}$}

V narečju sta v nasprotju s knjižnim jezikom mogoča tako sklop dveh enakih soglasnikov kot podaljšani soglasnik (kar omenja že Rigler 1981: 68) 's:a:ba = s sabo', 's'uọršce = iz soržice, z'ak'riža = iz Zakriža T, šru'nične $(\approx s$ 'šunične 'iz'). Ker za /w/ v vzglasju pred nezvenečim nezvočnikom stoji $u, \mathrm{v}$ narečju ni soglasniških zvez [M] + N. Zveze med zapornikom in pripornikom so sicer redke, vendar zaradi redukcijskih pojavov pogostejše kot v knjižnem jeziku (Toporišič 1978: 33; Srebot-Rejec 1975b: 295), izjemna pa je zveza med zvenečima zlitnikom in pripornikom. Sklopi sf, šk, ks, fc, žb nastopajo samo v izposojenkah.

p $\quad$ p ̌s $-p^{\prime}$ šie $=$ bolhe, $\mathbf{p x}-p^{\prime} x a: l=$ pehali

t $\quad \mathbf{t k}-t^{\prime} k a: j n e, \mathbf{L}-\mathbf{s} t^{\prime} k i s t=$ takisto, $\mathbf{t x}-t^{\prime} x u: r=$ dihur

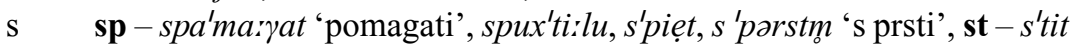
= pustiti, ste'denc, sto'ziẹ = steze, $s^{\prime}$ 'ta:čm $=\mathrm{s}$ takim, ss $-s^{\prime}$ si:kane = sesekane, s 'sa:ba (Oed), šs - s šu'nične 'muọke, sk - ska'čit, ska'lilu,

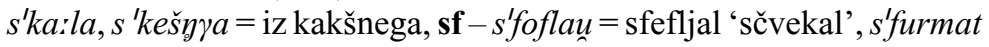
'izoblikovati', s 'fa:re 'iz', sc - scafad'ra:n 'scefran', scaj'nica 'seč', $s^{\prime}$ cisau = skisal, $s^{\prime}$ 'ci:pam = s cepom, šc $-s^{\prime}$ čistl, $s$ 'čimena $=\mathrm{s}$ kumino, $\mathbf{s x}-s^{\prime} x u:=$ suho, $s^{\prime}$ 'xiš $e^{\prime}$ 'iz'

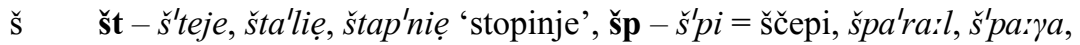

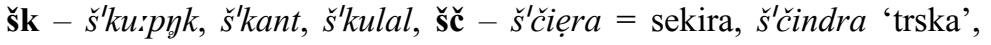
$\check{s}^{\prime}$ čidal $=$ skidali

k $\quad \mathbf{k t}-k^{\prime} t i e ̣ r, \mathbf{k s}-k^{\prime} e_{\text {: }}^{\prime} j l$ 'pomočnik pri obrtniku / v trgovini', $k^{\prime}$ sixt

f fc-f'curla 'rute' (Red)

c $\quad \mathbf{c p}-c^{\prime} p i c ̌, c^{\prime} p i l, \mathbf{c k}-c^{\prime} k i n$

$\mathbf{x} \quad \mathbf{x p}-\mathbf{L} x^{\prime}$ pit $=$ kupiti, $x^{\prime}$ pustu, $\mathbf{x t}-x^{\prime}$ tẹ:u, $x^{\prime}$ tiẹr $=$ kateri, $x{ }^{\prime}$ tem, $\mathbf{x s}-x$ 'sušcu $=\mathrm{k}$ Sušcu HI, $\mathbf{x s ̌}-x$ 'šestm, $\mathbf{x k}-\mathbf{Z} x^{\prime} k a: u=$ tkal, $x$ 'kešnm, $\mathbf{x c}-x$ 'ca:jtu 'pravočasno', x̌ $-x c ̌ e ' r a:(\mathrm{Rmn}), x$ 'čistm

b bd - b'ditt 'bedeti'

z $\quad \mathbf{z b}-z$ balli:t, zbez'la:l, z'bẹ:u = zbil, z 'ba:ba, zd - z'dẹ:u, z da'mače 'wọ:une 'iz', zz - zza'ri 'dozori', z'zidau = sezidal, $z$ 'zẹijle $=\mathrm{iz}$ zelja, 
$\mathbf{z z ̌}-z^{\prime z ̌ a} \gamma a l=$ sežagali, $z^{\prime z ̌ u o ̣ a m ~}=$ sežokam 'pretlačim', $z$ 'žica, $\mathbf{z} \gamma-z \gamma a^{\prime}{ }^{\prime} i:=$ zgorela, $z$ yas'ti: $=$ zgostila, $z^{\prime} \gamma a: \gamma a, z^{\prime}$ 'eplnam $=\mathrm{z}$ gepeljnom 'pripravo za vrtenje pogonske gredi, ki jo poganja vprežna živina'

ž $\quad \check{\mathbf{z} b}$ - ̌̌zba:le 'škornji', žbarc 'prva za lubjem odrezana deska', ž'buontari

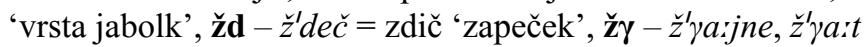

$3 \quad 3 \gamma-3^{\prime}$ ra:na $=$ cigana

$\gamma \quad \gamma \mathbf{b}-\gamma^{\prime}$ bigkl $=\mathrm{k}$ binklji 'mentrgi', $\boldsymbol{\gamma d}-\gamma^{\prime}$ 'du'xtari, $\boldsymbol{\gamma} \mathbf{z}-\gamma$ zar'nicam, $\gamma \check{\mathbf{z}}-\gamma^{\prime} \check{z} e \gamma n u$

g $\quad$ gd $-g^{\prime} d a: j, g^{\prime} d u r, g^{\prime} d u: r$

pripornik + zapornik

\begin{tabular}{|c|c|c|c|c|c|}
\hline & $\mathrm{b}$ & $\mathrm{p}$ & $\mathrm{d}$ & $\mathrm{t}$ & $\mathrm{k}$ \\
\hline$\gamma$ & + & & + & & \\
\hline $\mathrm{x}$ & & + & & + & + \\
\hline $\mathrm{s}$ & & + & & + & + \\
\hline$\check{\mathrm{s}}$ & & + & & + & + \\
\hline $\mathrm{z}$ & + & & + & & \\
\hline$\check{\mathrm{z}}$ & + & & + & & \\
\hline
\end{tabular}

pripornik + pripornik

\begin{tabular}{|c|c|c|c|c|c|c|c|}
\hline & $\gamma$ & $\mathrm{x}$ & $\mathrm{f}$ & $\mathrm{s}$ & $\check{\mathrm{s}}$ & $\mathrm{z}$ & $\check{\mathrm{z}}$ \\
\hline$\gamma$ & & & & & & + & + \\
\hline $\mathrm{x}$ & & & & + & + & & \\
\hline $\mathrm{s}$ & & + & + & + & + & & \\
\hline $\mathrm{z}$ & + & & & & & + & + \\
\hline$\check{\mathrm{z}}$ & + & & & & & & \\
\hline
\end{tabular}

pripornik + zlitnik

\begin{tabular}{|c|c|c|}
\hline & $\mathrm{c}$ & $\check{\mathrm{c}}$ \\
\hline $\mathrm{X}$ & + & + \\
\hline $\mathrm{f}$ & + & \\
\hline $\mathrm{s}$ & + & + \\
\hline$\check{\mathrm{s}}$ & & + \\
\hline
\end{tabular}

zapornik + zapornik

\begin{tabular}{|c|c|c|c|}
\hline & $\mathrm{d}$ & $\mathrm{t}$ & $\mathrm{k}$ \\
\hline $\mathrm{b}$ & + & & \\
\hline $\mathrm{t}$ & & & + \\
\hline $\mathrm{g}$ & + & & \\
\hline $\mathrm{k}$ & & + & \\
\hline
\end{tabular}


zlitnik + zapornik

\begin{tabular}{|l|c|c|}
\hline & $\mathrm{p}$ & $\mathrm{k}$ \\
\hline $\mathrm{c}$ & + & + \\
\hline
\end{tabular}

zapornik + pripornik

\begin{tabular}{|c|c|c|c|}
\hline & $\mathrm{x}$ & $\mathrm{s}$ & $\check{\mathrm{s}}$ \\
\hline $\mathrm{p}$ & + & & + \\
\hline $\mathrm{t}$ & + & & \\
\hline $\mathrm{k}$ & & + & \\
\hline
\end{tabular}

zlitnik + pripornik

\begin{tabular}{|l|l|}
\hline & $\gamma$ \\
\hline 3 & + \\
\hline
\end{tabular}

\subsection{3 $\mathrm{N}+\mathrm{Z}$}

Razmerja so podobna kot v knjižnem jeziku (Toporišič 1978: 34; Srebot-Rejec 1975b: 296), le v zvezi N + j je možnih nekoliko več povezav. Soglasniški sklopi tm, fl, fr, šr, šm, šw, ̌̌m, žn, kn, kj, $\gamma \mathbf{~ m}, \boldsymbol{\gamma \mathbf { w }}$ se pojavljajo v izposojenkah.

$+\mathrm{r} \quad$ pr - preda'ja:l, pra'xu (Red), pre'biẹrk 'izbirek', tr - tra'wie, tra'pa:l = trapali, sr - sra'mata, srejč'warl, s'ri:da, šr - Z š'ra:jn 'skrinja za žito', $\check{s}^{\prime}$ rit 'korak', kr - kra'it = krojiti 'cepiti, klati', kram'piẹr, k'ra:pše 'dereze', fr - f'riẹška, f'roxt 'tovor', f'ruүa 'pridelek', cr $-c^{\prime}$ 'ri.t $=$ cvreti,

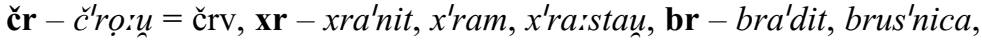
$b^{\prime} r a: d a, \mathbf{d r}-d r a^{\prime} b a: n=$ droban, dra'bit, d'rẹ:j = drevi, zr $-z^{\prime} e^{\prime} d i t$, z'ri:la, zrau'nik = zdravnik, žr $-z^{\prime} r e^{\prime} b i e ̣ t a, z^{\prime} r i: t=$ žreti, ž'rọ:u = žrv

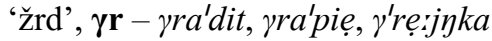

+1 $\quad$ pl - pla'ča: (del. -l, ž ed), pla'šur = plaščur 'potepuh', Ra p'lesna 'osevek', tl - t'la, t'li:t = tleti, sl - s'la:ba, s'lina, s'lušt, kl - kla'ba:sa, kla'nica 'kolnica', k'liẹplem, fl -flaš'kuọ, f'lẹ:ut 'tekoča, lepljiva, židka snov', fla:jda 'halja', čl - č'la:jk= človek, č́lẹ:jn = člen 'gleženj', xl

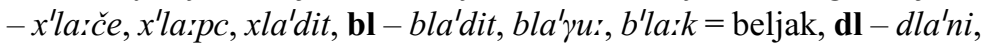
zl - zla'mit, zle'ti:t = zleteti, žl - žla'budra (Ied), žle'bowi, žlliẹmporxa 'loputa', $\boldsymbol{\gamma l}-\gamma^{\prime} l a: w a, \gamma l i s ' t i e$ (Imn), $\gamma^{\prime} l a: t k=$ gladek

+w $\quad$ sw - s'wẹ:jnsku, s'wilka 'valjar', šw - šwa'xatna, š'wa:jfarca 'vrsta žage', š'warc ‘črn konj', kw - k'wars, kwan'ta: ${ }^{\prime}, k w a r^{\prime} t i n, \mathbf{c w}-c^{\prime} w e k$, $c^{\prime} w i: t=$ cvet, $c^{\prime}$ wilje (sed. 3mn), čw $-\check{c}^{\prime}$ wiẹla 'čebela', $\mathbf{x w}-x w a$ lit, $x^{\prime} w e$ :jčmu, $x$ we'lič 'nač, $\mathbf{d w}-d^{\prime} w a r, d w a^{\prime} n a{ }^{\prime} j s t, \mathbf{z w}-z w a{ }^{\prime} n i: \gamma a t=\mathrm{zo}-$ negati, zwa'lit, z 'wa:m, ̌̌w - ̌̌weč'ka:jne 'blebetanje', ̌̌wa'li (Red), $\check{z}^{\prime}$ wiẹrya 'klepetav človek', $\gamma \mathbf{w}-\gamma^{\prime}$ want, $\gamma^{\prime}$ wiẹrat

$+\mathrm{m} \quad \mathbf{t m}-t^{\prime}$ min $=$ Tolmin $\mathrm{T}, \mathbf{s m}-$ sma'dit, sme'ta:na, s'mala, šm $-\check{s}^{\prime}$ ma:rje

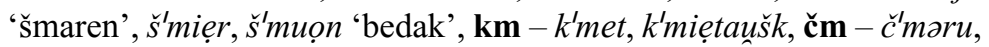
$\mathbf{x m}-x^{\prime} m a: l, \approx \mathbf{P d} x^{\prime} m i e ̣ t a u s ̌ k, x$ 'ma:š, $\mathbf{z m}$ - zma'čit, z'mẹ:jleje (sed. 3mn), z 'ma:na, žm - žmaxt 'okus', ž'muklci 'volneni sprimki', $\gamma \mathbf{m}$ rmaj'niẹ (Imn), $\gamma^{\prime} \max$ 'mir' 
$+\mathrm{n} \quad$ tn $-t^{\prime}$ na:la, sn - s'nap, s'na:rsk = senarski, s'niẹdu, šn $-\approx \check{s}^{\prime} n e z ̌ e t$ = senožet, š'na:jtaxa 'cimraka', kn - k'naf 'gumb', k'niẹdlni, cn -

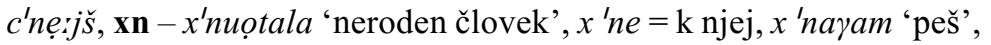
$\mathbf{d n}-d^{\prime} n a, d^{\prime} n a: r, \mathbf{z n}-z n a ' s i l, z^{\prime} n a: t$, žn - žneda'rije, žnu:ra, $\gamma \mathbf{n}-$

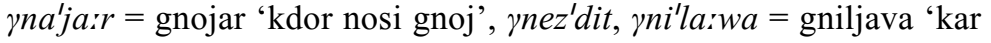
je gnilo'

$+\mathrm{j} \quad \mathbf{p j}-$ pja'ni, p'ja:ča, sj - s'ja:uka 'košara za seme pri sejanju', kj k'ja:ntarca, cj - c'ja:xta 'vlačuga', xj - x 'juncu, dj - d'ja:t, zj - z'ja:la, $z^{\prime}$ jutre, zje'zilu

\begin{tabular}{|c|c|c|c|c|c|c|}
\hline & $\mathrm{r}$ & $\mathrm{l}$ & $\mathrm{w}$ & $\mathrm{m}$ & $\mathrm{n}$ & $\mathrm{j}$ \\
\hline $\mathrm{p}$ & + & + & & & & + \\
\hline $\mathrm{b}$ & + & + & & & & \\
\hline $\mathrm{f}$ & + & + & & & & \\
\hline $\mathrm{t}$ & + & + & & + & + & \\
\hline $\mathrm{d}$ & + & + & + & & + & + \\
\hline $\mathrm{s}$ & + & + & + & + & + & + \\
\hline $\mathrm{z}$ & + & + & + & + & + & + \\
\hline $\mathrm{c}$ & + & & + & & + & + \\
\hline$\check{\mathrm{s}}$ & + & & + & + & + & \\
\hline$\check{\mathrm{z}}$ & + & + & + & + & + & \\
\hline$\check{\mathrm{c}}$ & + & + & + & + & & \\
\hline $\mathrm{k}$ & + & + & + & + & + & + \\
\hline$\gamma$ & + & + & + & + & + & \\
\hline $\mathrm{x}$ & + & + & + & + & + & + \\
\hline
\end{tabular}

\subsubsection{Z + N}

(1) Možni so le sklopi u z zvenečimi nezvočniki, zato za polovico manjši nabor kot v knjižnem jeziku (Srebot-Rejec 1975b: 296). Sklopi z nezvenečimi nezvočniki se uresničujejo v govorni verigi, prim. 4.

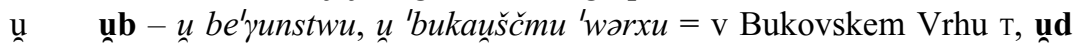
- uda'wi:la = ovdovela, udu'šit, u da'lin, unz - ư⿱ 'za:me, u'zemle (Ted),

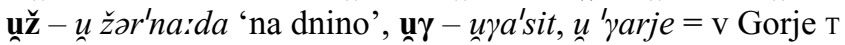

(2) Drugi zvočniki so v položaju pred nezvočnikom zlogotvorni:

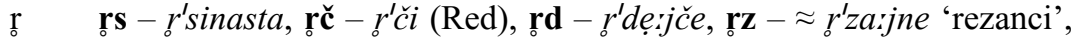
řž $-r_{0}^{\prime}$ žiẹn

$1 \quad$ lp - l'pina, l'pu:, lt - l'tiẹrna 'svetilka', lo - l'siẹn, l'sica, lo - l'biyke

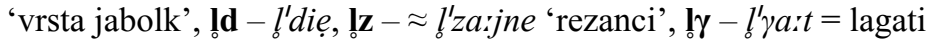

m $\mathbf{m} \mathbf{x} x-m_{o}^{\prime} x i: r=$ mehur, mo'xowi, mb-mo'ba:žeu 'bombažev', $\mathbf{m} \mathbf{z}-m_{o}^{\prime} z e l c i$ 'mozoljci', mǒz - moža:t 'mižati'

no $\mathbf{n} \mathbf{k}-\eta^{\prime}$ ka:mor 'nikamor', no $-n_{0}^{\prime} c u o j, n_{o}^{\prime} c a: j t$

\subsection{Tridelni sklopi}

Od zvočnikov lahko na prvem mestu sklopa stoji le $u$. Če soglasniku sledita dva zvočnika, je prvi vedno $m$. 
1.2.1 $\mathbf{Z}+\mathbf{Z}+\mathbf{Z}$

Srebot-Rejec (1975a: 13) za knjižni jezik navaja samo zaporedje [w]lj.

$+\mathrm{m}+$

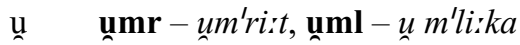

1.2.2 $\mathbf{N}+\mathbf{Z}+\mathbf{Z}$

Ta skupina je v narečju precej redkejša zaradi odsotnosti zaporedij $l+j, n+j$ (prim. Srebot-Rejec 1975a: 12).

(1) $+\mathrm{m}+$

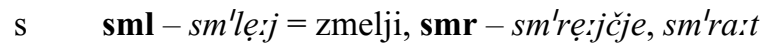

z $\quad$ zml-zm'la: ̌̌enu, z m'li:kam

x $\quad \mathbf{x m l}-x m^{\prime} l i r k u$

(2) $+1+$

$$
\mathbf{p l} \mathbf{w}-p_{o}^{\prime} \text { wic }=\text { plevic }(\mathrm{Rmn})
$$

\subsection{3 $\mathrm{Z}+\mathrm{N}+\mathrm{Z}$}

(1) Sem spadajo le zveze s predlogom $u$.

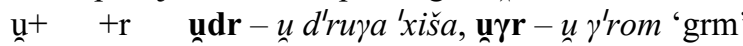

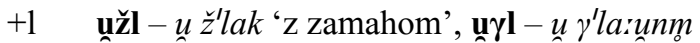

$+\mathrm{m} \quad$ unjm - u $\gamma^{\prime}$ ma:jna

$+\mathrm{n} \quad \mathbf{u d n}-u d^{\prime}$ 'nex 'na dnu', ư $\gamma \mathbf{n}-u \gamma^{\prime}$ 'naju 'gnoju'

(2) Drugi zvočniki pred $\mathrm{N}+\mathrm{Z}$ postanejo zlogotvorni, za sklop cj v navadni medsamoglasniški legi ni potrditve.

$\mathrm{r}+\quad \mathrm{rcn}-r c^{\prime} n i j e$

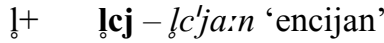

n+ $\mathbf{n} \mathbf{n} \mathbf{j}-\mathbf{L} n c_{0}^{\prime} j a: n$

1.2.4 $\mathbf{Z}+\mathbf{N}+\mathbf{N}$

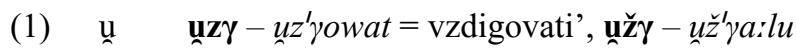

(2) $\quad$ l lsk - ls s'kina

\subsection{5 $\mathrm{N}+\mathrm{N}+\mathrm{Z}$}

Tako kot v knjižnem jeziku je to najpogostejša skupina. Pri tem lahko na prvem mestu sklopa poleg $\mathrm{v}$ knjižnem jeziku običajnih pripornikov $/ z /, \mid s /$ (Toporišič 1978: 36) oz. $/ \check{s} /, / x /$ (Srebot-Rejec 1975b: 300) stojita še $/ t /$ in $/ p /$. Tem poleg v vzglasju navedenih dvodelnih sklopov lahko sledi še sklop $t+w$ (v vzglasju so samo primeri z asimiliranim $w$-jem - 'tuij 'tvoj').

$+\mathrm{r} \quad \mathrm{s}^{+} \quad \mathbf{s p r}$ - spra'cirsje 'procesija', sprewab'lẹjčt, s p'rižnce, str stra'xowi, stre'pi, s t'ruyam 's predali', skr - skra'pije 'razkropijo', skri'wa:l (del. -l, m mn), s k'ruopam, sfr - sf'ra:čena 'skrhana', s f'rišne 'župe 'iz', sxr - sxra'nit, s x'ruške

š+ $\quad$ špr - ̌sp'rixta 'cunja', štr - ̌st'rudl, št'rẹ:jk = štrik 'vrv', škr škra'pi, šk'ripc 'členek'

$\mathrm{x}^{+} \quad \mathbf{x k r}-x k^{\prime} r a: t u$

$\mathrm{z}^{+} \quad \mathbf{z b r}-z b r a^{\prime}$ na:t, $z$ bru'sit, $\mathbf{z d r}-z d r a^{\prime} b i=$ zdrobi, $z d^{\prime}$ 'ruozat 


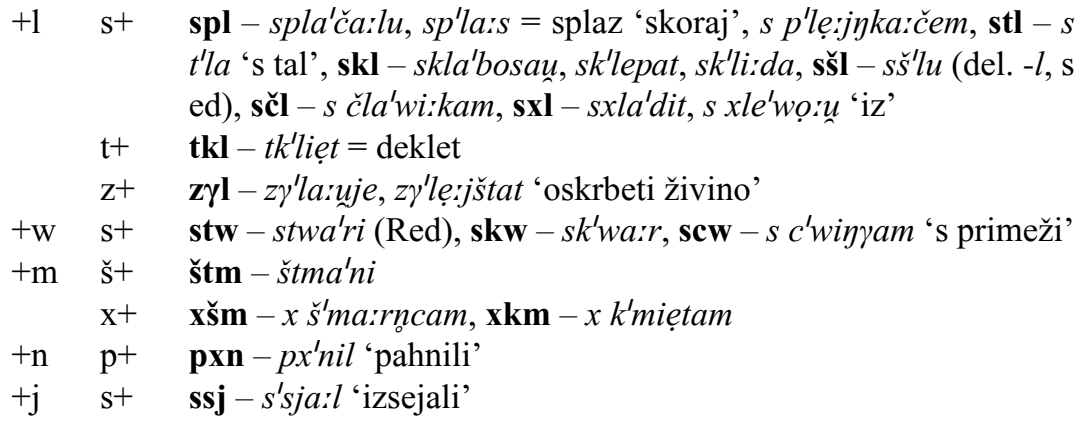

\subsection{6 $\mathbf{N}+\mathbf{N}+\mathbf{N}$}

Narečno je sklapljanje z začetnim /p/ (prim. Toporišič 1978: 36). T. SrebotRejec (1975a: 11) navaja samo sklop stk.

p+ $\quad$ pst $-p s^{\prime} t i l$ 'pustili', ps'tu: 'pusto'

s+ $\quad \mathbf{s p x}-s p^{\prime} x a: l, \mathbf{s s ̌ p}-s \check{s}^{\prime}$ pexam, scp $-s c^{\prime}$ piunco

$\mathrm{x}^{+} \quad \mathbf{x s p}-x s^{\prime}$ powedi

1.2.7 $\mathbf{N}+\mathbf{Z}+\mathbf{N}$

je zveza z zlogotvornima zvočnikoma $l$ in $n$.

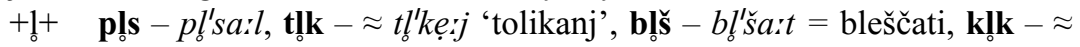
$k l$ 'kẹ:j 'tolikanj'

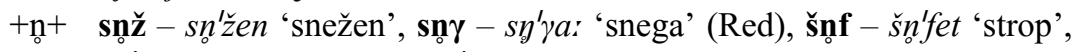
šn'fiẹce 'obujki', žno - žn'da:ri

\section{3 Štiridelni sklopi}

Iz gradiva je mogoče izluščiti samo dva tipa zaporedij členov (prvi člen je s), kar je manj kot v knjižnem jeziku (Toporišič 1978: 36). V gradivu ni zaporedij $\mathrm{N}+\mathrm{N}+\mathrm{Z}+\mathrm{Z}$ in $\mathrm{Z}+\mathrm{N}+\mathrm{N}+\mathrm{Z}$, ki sta potrjeni v gradivu za knjižni jezik (Srebot-Rejec 1975a: 16; 1975b: 304).

\subsection{1 $\mathbf{N}+\mathbf{N}+\mathbf{N}+\mathbf{Z}$}

stkn - stk'nil 'staknili'

\subsection{2 $\mathbf{N}+\mathbf{N}+\mathbf{N}+\mathbf{N}$}

$$
\text { spst - sps'til 'spustili' }
$$

1.3.3 Drugo so različne (lahko tudi petčlenske) povezave z zlogotvornimi zvočniki:

$\mathbf{Z}+\mathbf{N}+\mathbf{Z}+\mathbf{N}$

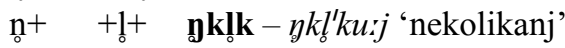

$\mathbf{N}+\mathbf{Z}+\mathbf{N}+\mathbf{Z}$

$+1+\quad \mathbf{k l t} \mathbf{j}-k l_{o} t^{\prime} j u o=$ kletjo, plzzj - plz'juọna 'pokojnine' (Red)

$\mathbf{N}+\mathbf{N}+\mathbf{Z}+\mathbf{N}+\mathbf{N}$

$+1+\mathbf{s} \mathbf{s} \mathbf{l} \mathbf{s t}-$ skls ${ }^{\prime} t i l$ 


\section{$2 \quad$ Izglasni sklopi}

V izglasju stojijo sklopi z dvema in tremi, redko štirimi soglasniki.

\subsection{Dvodelni sklopi}

\subsection{1 $\mathrm{Z}+\mathrm{Z}$}

Na prvem mestu lahko stojita le $u$ in $j$, drugi zvočniki se povezujejo z zlogotvornimi zvočniki, pri čemer sta možni tudi zaporedji dveh enakih zvočnikov (ll in $n n$ ). Zaradi že omenjenih narečnih razvojev, ki so pomnožili pojavitve fone$\mathrm{ma} / \mathrm{j} /$, in samoglasniške redukcije ta kategorija ne izkazuje pretežno prevzetega besedja, tako kot to velja za večino sklopov v knjižnem jeziku (Toporišič 1978: 37).

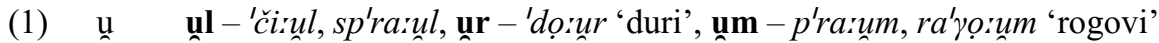
(Omn), un - 'čoiun, 'raiun 'ravno'

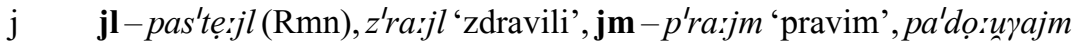
'po dolgem', b'rizzajm 'brezovim' (Oed), jn - 'cuijn (Rmn), 'pa:jn, ka'rẹijn

(2) r $\quad \mathbf{r m}$-'furm, 'ja:rm, 'kurm (sed. 1ed), rno - L baz'jern 'kvas', 'čərn, 'fa:rn $1 \quad$ ll - u'sill, $\mathbf{l m}_{\circ}$ - 'bi:lm, c'wilm, de'belm (Med), $\mathbf{l n}_{\circ}$ - 'maln, 'peln, pe'teln, čébiẹln

m $\quad$ ml - '̌siml, 'zeml (Med), mn - 'ka:mn, 'tomn 'temen'

n n! - 'cinl, p'la:nl, nm - p'ledenm, l'siẹnm (Oed), wa žiẹnm 'oženim', nn - '̌iẹnn

\subsection{2 $\mathbf{N}+\mathbf{N}$}

Ta skupina sklopov se precej razlikuje od ustrezne v knjižnem jeziku, čeprav je število ugotovljenih povezav v obeh skorajda enako (Srebot-Rejec 1975: 308-309; prim. Toporišič 1978: 38). V knjižnem jeziku je devet sklopov, ki jih ni v narečnem gradivu (tp - sodb, kp - prerokb, čp - enačb, kt - fakt, $\mathbf{c t}$ - lect, $\mathbf{f t}$ - lift, fk - filozofk, tc - vratc, $\mathbf{k} \check{\mathbf{s}}$ - rikšs), to pa je od knjižnega

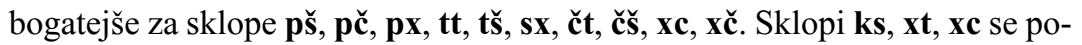
javljajo samo v izposojenkah. Zveza dveh pripornikov je v izglasju izjemna (en sam potrjen primer - sx). Sklopov s soglasnikom $f$ v gradivu ni.

p $\quad \mathbf{p t}-{ }^{\prime} k u p t$, 'wa:pt, ps - 'ka:ps = kapus 'zelje', p̌s - 'kupš, 'ra:pš (sed. 2ed), 'li:pš, pk - 'bapk, 'repk, pc - 'cepc, 'kopc = kupec, p̌c $-s^{\prime} n a p \check{c}=$ snopič, wa'lup $\check{c}=$ olupki, $\mathbf{p x}-t^{\prime}$ ri:px $=$ trebuh

t $\quad \mathbf{t t}-$ 'xatt 'hoditi', tš - 'čutš, 'witš, tk - 'piẹtk, 'ri:tk 'redek'

s $\quad \mathbf{s p}$ - 'isp, st - 'ba:udast 'gubast', wa'bist 'ledvica', sk - 'jesk, 'nisk, 'u:sk 'vosek', sc - 'jaisc 'jazbec', 'kasc, 'posc 'pezdec', sx - 'bosx 'bezeg'

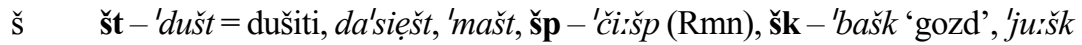
= jožek 'slepo črevo', šc - 'wešc = vežic $(\mathrm{Rmn}), p^{\prime} r i \cdot \check{s} c=$ prešc $(\mathrm{Rmn})$, $t^{\prime} r u s ̌ c=$ tružici 'ribežnu za repo' (Med), šč - 'bašč 'božič', 'kuơ̌č = koščič 'kosek', yas'pašč 'gosposki'

k $\quad \mathbf{k s}-{ }^{\prime} a: k s$ 'os', 'biks 'loščilo za čevlje'

c $\quad \mathbf{c k}-\approx$ 'kock' $p$ rašiček' 


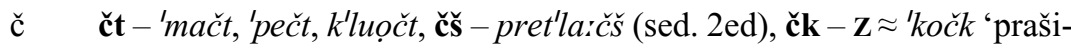
ček', be'račk 'košarica', ka'fečk = kafetček 'kavica'

x $\quad \mathbf{x t}$ - 'rixt 'jedi' (Rmn), 'sixt, 'taxt 'stenj', $\mathbf{x k}$ - 'bu:xk 'bogek', xc - 'uoxoc

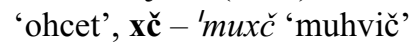

pripornik + zapornik

\begin{tabular}{|c|c|c|c|}
\hline & $\mathrm{p}$ & $\mathrm{t}$ & $\mathrm{k}$ \\
\hline $\mathrm{x}$ & & + & + \\
\hline $\mathrm{s}$ & + & + & + \\
\hline$\check{\mathrm{s}}$ & + & + & + \\
\hline
\end{tabular}

- pripornik + zlitnik

\begin{tabular}{|c|c|c|}
\hline & $\mathrm{c}$ & $\check{\mathrm{c}}$ \\
\hline $\mathrm{x}$ & + & + \\
\hline S & + & \\
\hline$\breve{S}$ & + & + \\
\hline \multirow{2}{*}{\multicolumn{3}{|c|}{ zapornik + zap }} \\
\hline & & \\
\hline & $\mathrm{t}$ & $\mathrm{k}$ \\
\hline $\mathrm{p}$ & + & + \\
\hline $\mathrm{t}$ & + & + \\
\hline
\end{tabular}

zapornik + zlitnik

\begin{tabular}{|c|c|c|}
\hline & $\mathrm{c}$ & $\check{c}$ \\
\hline $\mathrm{p}$ & + & + \\
\hline
\end{tabular}

zlitnik + zapornik

\begin{tabular}{|c|c|c|}
\hline & $\mathrm{t}$ & $\mathrm{k}$ \\
\hline $\mathrm{c}$ & & + \\
\hline$\check{\mathrm{c}}$ & + & + \\
\hline
\end{tabular}

zapornik + pripornik

\begin{tabular}{|c|c|c|c|}
\hline & $\mathrm{s}$ & $\check{\mathrm{s}}$ & $\mathrm{x}$ \\
\hline $\mathrm{p}$ & + & + & + \\
\hline $\mathrm{t}$ & & + & \\
\hline $\mathrm{k}$ & + & & \\
\hline
\end{tabular}

zlitnik + pripornik

\begin{tabular}{|c|c|}
\hline & $\check{\mathbf{s}}$ \\
\hline$\check{\mathrm{c}}$ & + \\
\hline
\end{tabular}




\subsection{3 $\mathrm{Z}+\mathbf{N}$}

Povezave z vsemi nezvočniki so potrjene le pri $j$. Te zveze so zaradi pogostega prehodnega $j$ in razvoja $w>j$ pred $\check{e}$ in $i$ močneje zastopane kot v knjižnem jeziku (gl. gradivo pri Srebot-Rejec 1975: 309). Na sklope lx, rs, mp, mf, unp, jp, jt, jf naletimo le v prevzetih besedah.

r $\quad \mathbf{r p}$-'sarp, 'fa:rp 'farb', 'li:šerp 'leščerb', rt - 'ajykart, 'ba:rt, rs - 'biẹrs = berz 'ohrovtov' (Rmn), řs - 'boršs, 'dorš (vel. 2ed), rk - 'curk, 'siẹrk 'koruza', pre'biẹk 'izbirek', rc - 'karc $=$ korec, 'kurc, 'warc $=$ vrvic $(\mathrm{Rmn}), \mathbf{r c ̌}$ - 'ledarč 'radič', 'yarč = gorki 'topli', rx - 'biẹštərx 'mizarska miza', 'durx, 'piẹrx

$1 \quad \mathbf{l p}$ - 'welp 'velb', It - 'bi:lt 'beliti', lš - 'bu:lš, 'diẹtelš = deteljišču (Med), pa'bi:lš (sed. 2ed), lk - 'fu:lk, 'pa:lk 'pajek', 'polk 'pèšk' (Rmn), lc - 'mulc 'krvavic' (Rmn), de'biẹlc 'vrsta fižola', 'fasselc 'sodček za pivo', ľc - 'palč 'polič', sa'kalč = sokolič, lf - 'yalf'goljuf', lx - c'wilx 'vrsta blaga'

u $\quad$ up - wor'la:up 'počitnice', unt - 'ba:ut 'gub' (Rmn), 'jẹraut 'skrbnik', nap'ra:ut, uxs - 'a:uيs, L f'lo:us 'sani za vleko hlodov', uيš - 'bu:rauš,

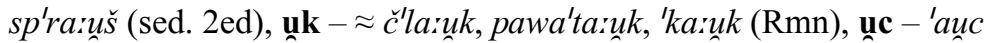
= ovc (Rmn), 'ca:rtauc, sa'niuc 'sani za vleko hlodov', uيč - na'tọ:uč (vel. 2ed), uxx - 'do:ux 'dolg', 'po: ux

m $\mathbf{m p}-{ }^{\prime}$ wamp, $\mathbf{m f}-\check{s}^{\prime}$ tomf 'nogavica', mc - 'sa:mc

n nt $-{ }^{\prime}$ cent, 'ci:nt = ceniti, 'cunt 'cunj' (Rmn), ňs - 'yuonš, x'ra:nš (sed. 2ed), $\mathbf{n k}$ - 'bayk 'lesena posoda', 'cink, nc - 'nunc 'boter', 'tuonc 'popek', 'danc 'danes', nč - 'čiẹnč (Rmn)

j $\quad \mathbf{j p}$ - '̌saijp 'šip', jt - 'baijt (Med), 'ca:jt, js - wa'be:js, kaka'daijs, ǰs -

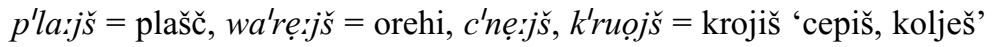
(sed. 2ed), jk - člla:jk = človek, 'ne:jk = neki, št're:jk = štrik 'vrv', jf žla:jf 'zavora', 'fa:jf (Rmn), jc - 'bukajc 'bukvi', 'ilajc = ilovici (Med), ǰ̌ $-t^{\prime}$ rẹ:jč 'tretji', jx - 'ca:jx 'vrsta blaga', $k^{\prime}$ ruxajx 'kruhovih'

\begin{tabular}{|c|c|c|c|c|c|c|c|c|c|}
\hline & $\mathrm{p}$ & $\mathrm{f}$ & $\mathrm{t}$ & $\mathrm{s}$ & $\mathrm{c}$ & $\breve{\mathrm{s}}$ & $\check{\mathrm{c}}$ & $\mathrm{k}$ & $\mathrm{x}$ \\
\hline $\mathrm{r}$ & + & & + & + & + & + & + & + & + \\
\hline $\mathrm{l}$ & + & + & + & & + & + & + & + & + \\
\hline $\mathrm{u}$ & + & & + & + & + & + & + & + & + \\
\hline $\mathrm{m}$ & + & + & & & + & & & & \\
\hline $\mathrm{n}$ & & & + & & + & + & + & + & \\
\hline $\mathrm{j}$ & + & + & + & + & + & + & + & + & + \\
\hline
\end{tabular}

\subsection{4 $N+Z$}

je zveza z zlogotvornimi zvočniki $l, m, n$.

$1 \quad$ pl $-s^{\prime}$ tepl, 'ka:pl (Rmn), tl - t'ruotl, 'patl 'potlej', sl - 'misl (sed. 3ed), 'jaisl (Rmn), šl - 'pušl 'šop', 'kaišl, kl - 'dirkl, 'cuokl (Rmn), 'rekl, cl - 'cucl, škar'nicl, čl - 'puọ̌l, u'ničl, b! - 'ra:bl, s'ta:bl = stebel 'debel' (Rmn), dl - 'badl = bodli, 'siẹdl, f'ruọdl 'vejnik', zl - 'ya:zl, žl - 'luọzl

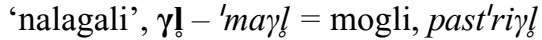


m tmo - 'čutm, 'luọtm (sed. 1ed), sm - 'kasm 'omara', 'pirsm = pesem,

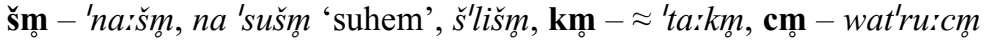

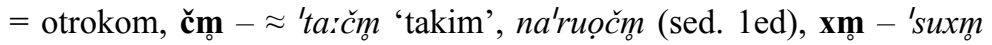
(Oed), bm - pa'za:bm, s'la:bm, dm - 'čudm, 'widm, m'la:dm, zmo 'pa:zm (sed. 1ed), žm - 'čižmo, 'liẹžm (sed. 1ed), čen'tiẹžm 'stoti del lire', $\gamma \mathbf{m}-$ 'namd'ruүm = nam drugim 'nam'

n $\quad \mathbf{t n}-$ 'ćirtn 'verig', 'petn = petim, nasp'rustn, sn - 'kosn 'pozno', 'nuosn 'nosim', pa'tisn (vel. 2ed), šn - 'lušn = lušten, kn - u'lukn (Med), 'cikn (vel. 2ed), cn - 'locn 'držaj', 'nucn 'uporaben', čn - 'tiẹčn, m'li:čn, $\mathbf{x n}$ - 'ca:xn, 'mixn = majhen, 'poxn (vel. 2ed), bn - 'bu:bn, xa'dabn, $\mathbf{d n}-{ }^{\prime} c ̌ u d n,{ }^{\prime}$ pu: $d n=$ podenj, 'siẹdn = sedem), zno - 'ka:zn, na'ra:zn,

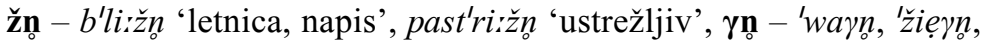
$d^{\prime}$ riện (vel. 2ed)

\subsection{Tridelni sklopi}

\subsubsection{Z + N + N}

je najpogostejše zaporedje. Medtem ko v to kategorijo v knjižnem jeziku spadajo predvsem besede tujega izvora, je v cerkljanskem narečju razmerje med domačim in prevzetim enako kot pri drugih sklopih. Kot zanimivost velja dodati, da npr. že omenjeno podjunsko narečje (Zdovc 1972: 51) pozna le tri sklope te vrste. Nezvočniški par je navadno zveza pripornika z zapornikom ali zveza dveh zapornikov, torej je zadnji člen praviloma zapornik. Edini primer povezave zapornika s pripornikom je sklop pš.

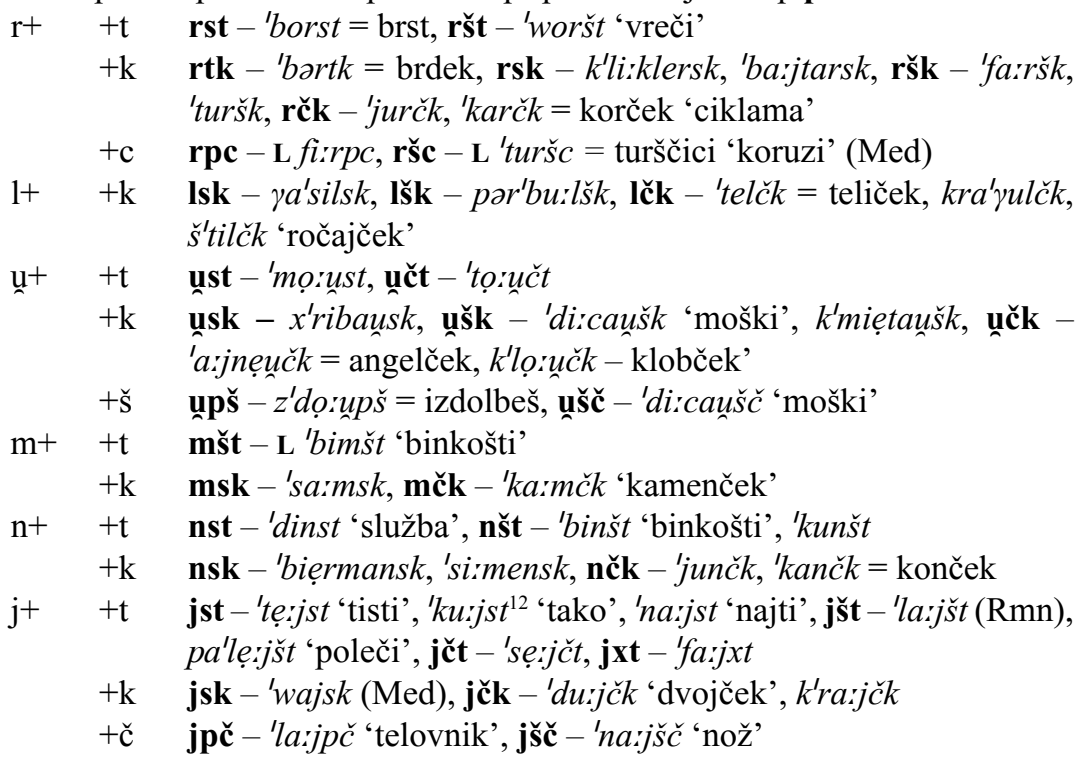

${ }^{12}$ Po Ramovšu (1935: 86) analogična tvorba k leksemu 'tu:jst $(\leftarrow$ 'tu:jsta $<$ tô-isto) glede na razmerje tak: kak. 
2.2.2 $\mathbf{N}+\mathbf{N}+\mathbf{N}$

p+ $\mathbf{p s t}-{ }^{\prime}$ sapst, 'ziẹpst, pay'ra:pst 'pograbiti', pčk - 'kopčk, x'li:pčk

št $\quad$ ščk - 'kuoščk

2.2.3 $\mathrm{Z}+\mathrm{Z}+\mathbf{N}$

Soglasniški sklop lahko pri takem zaporedju členov nastane le pri zvezah $u$ $+m+\mathrm{N}$ in $j+n+\mathrm{N}$.

(1) u u ump -'ro:ump (Med), unmf - k'la:unf (Rmn)

j $\quad$ jnš - 'ma:jnš, jnk - 'rẹ:jyk 'obroč', 'šẹjgk 'darilo', wab'rujgk = obronek, jnc $-j e$ 'sẹ:jnc = jesenec 'jeseni rojena žival', 'uojnc $=$ ojnic $(\mathrm{Rmn})$, jnč $-p a^{\prime} \gamma a: j n \check{c}=$ poganjič, ${ }^{\prime} k a j n \check{c}=$ konjič

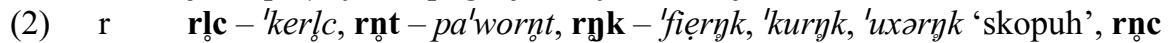
- 'co:uparnc, 'lu:jtorñc (Ded)

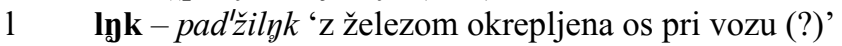

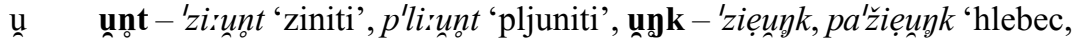
ki ga dninarice dobijo po žetvi', unno - 'ziẹnnc = zelnici (Med)

m $\mathbf{m g k}-s^{\prime} l a: m \eta k$

2.2.4 Druga zaporedja so zveze z zlogotvornimi zvočniki.

$\mathbf{Z}+\mathbf{Z}+\mathbf{Z}$

$\operatorname{lnm}-\check{c} e^{\prime} b i e ̣ \operatorname{lnm}(\mathrm{Med})$

$\mathbf{Z}+\mathbf{N}+\mathbf{Z}$

Sklopov rf, mp, $\mathbf{n k ~ i n ~ n z ~ n i ~ m e d ~ o b i c ̌ a j n i m i ~ d v o c ̌ l e n s k i m i ~ m e d s a m o g l a s n i s ̌ k i m i ~}$ sklopi.

+l ršl - 'poršl l = prišli, rk! - 'biẹrkl 'bergelj', 'burkl $(\mathrm{Rmn}), \mathbf{r f l}$ - 'purfl, rxl - 'karxl, rzl - 'marzl, mpl - k'riempl, 'ka:mpl 'vrsta glavnika', ntl 'muontl, 'bentl = bentili, $\mathbf{y k l}$ - 'bijkl (Med), ncl - b'riẹcl, $k^{\prime} r a: n c l$, nzl

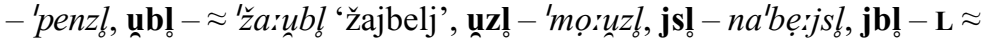
'̌a

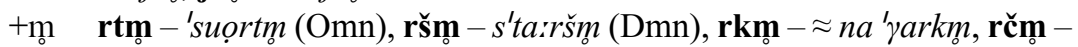

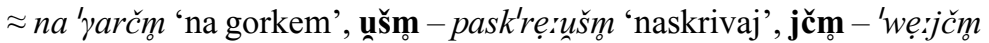
(Med)

+no $\quad$ rtno - 'kartno $=$ krtin $(\mathrm{Rmn})$, ršn - 'ku:lkaršñ, rčno - 'fiẹrčn 'radoveden',

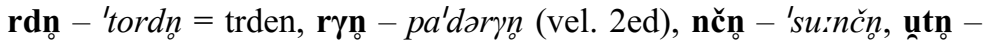

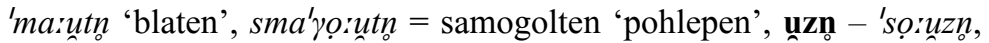

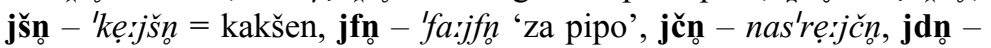
'la:jdn 'stranišče', p'rẹ:jdn

$\mathbf{N}+\mathbf{Z}+\mathbf{Z}$

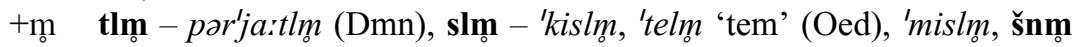
- 'kešnm = kakšnim (Oed), xnm - 'laxnm (Oed), brm - 'dabrm (Oed), znm - ba'li:znm (Oed)

+n $\quad$ pln - ' 'epln 'gepelj', tlno - u'čitln, slno - 'misln (del. -l, m mn), Pd žiẹsln 'stol z naslonjalom', kln - 'cikln, cln - 'locln 'držaj', 'rucln 'ročaj', y $\mathbf{l n}$ - 'na: $\gamma \ln , u^{\prime} z i \gamma \ln$ (del. -l, m mn) 
$\mathbf{N}+\mathbf{Z}+\mathbf{N}$

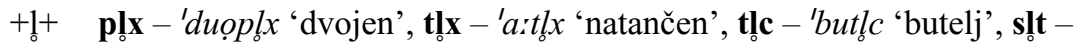
$z^{\prime}$ mislt se 'spomniti se', slı̌s - 'mislšs (sed., 2ed), sloc - 'karslc 'nabiralnik', 'maislc, šlı - 'pušlc, klıc - 'xa:klo 'kvačka', d'riklc 'vprežna prečka',

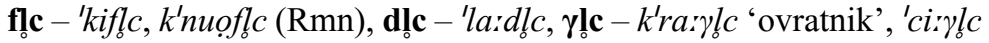
'list papirja'

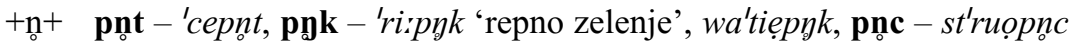

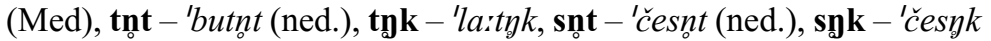

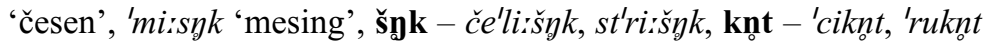
(ned.), kncc - 'luknc (Med), fnot - k'lafnt, čnk - žličnk, $\mathbf{x n o t ~ - ~ ' c ̌ i x n o t ~ = ~}$ kihniti, 'poxnt = pahniti, xnk - 'la:xyk 'lehnjak', bnt - 'cobnt 'brcniti',

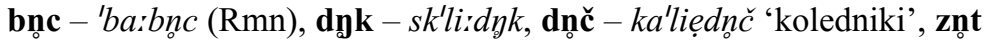
- z'muznt, d'ruoznt 'drezniti', zyk - p'ra:zøk, znoc - že'lizznc (Med), žnk

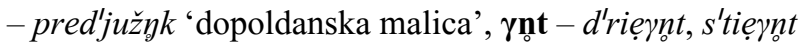

$$
\mathbf{N}+\mathbf{N}+\mathbf{Z}
$$

Sklopa kš ni med običajnimi medsamoglasniškimi.

+1 pcl - wa'ka:pcl '(čevlje) opremili s kapicami' (del. -l, m mn), stl 'čistl, ksl - d'ra:ksl 'strugarsko orodje'

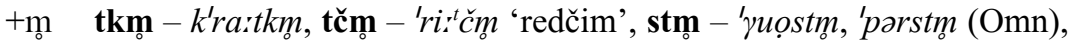
škm - 'maškm, 'teškm (Ded)

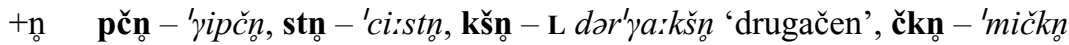

\section{3 Štiridelni sklopi}

Štiridelen je lahko samo sklop z $j / u$ na prvem mestu, in sicer le v povezavi dveh zvočnikov z dvema nezvočnikoma. V knjižnem jeziku imajo končni štiridelni sklopi strukturo Z+N+N+N (Srebot-Rejec 1975b: 314).

2.3.1 $\mathrm{Z}+\mathrm{Z}+\mathrm{N}+\mathbf{N}$

(1) u un určk - 'mo:ururčk 'murenček'

j jnsk - '̌̌ẹijnsk, cerk'laijnsk, jnčk - 'kuojnčk

(2) $+1+$ rlosk - 'kerlsk 'postaven'

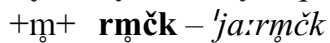

\subsubsection{Zveze z zlogotvornimi zvočniki}

Sklopov unč , rkl, rzl, ntl, jst, jxt in jnšt ni med običajnimi medsamoglasniškimi.

$\mathbf{Z}+\mathbf{Z}+\mathbf{N}+\mathbf{Z}$

$+1 \quad$ jng $\gamma \mathbf{l}-{ }^{\prime} k a: j \eta \gamma l(\mathrm{Rmn})$

$+\mathrm{m}_{\mathrm{o}} \quad \mathbf{j} \mathbf{j} \mathbf{k m}-p \mathbf{a}^{\prime}$ tẹ:jykm $=$ po tenkem

+ n unčn $-w a$ 'ma:unčn 'omotičen'

$\mathbf{Z}+\mathbf{N}+\mathbf{Z}+\mathbf{Z}$

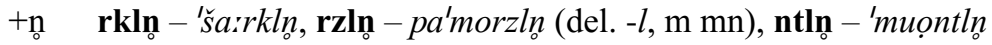

$\mathbf{Z}+\mathbf{N}+\mathbf{Z}+\mathbf{N}$

$+1+\quad$ rklo - 'fiẹrklc 'četrt' 
$+n_{0}+$ lčnk - 'mulčnk 'rog za polnjenje klobas', rknt - 'corknt, c'warknt 'po-

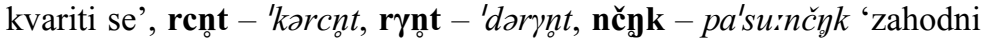

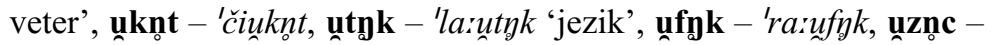
'mo:uznc (Med), ưžno - 'ta:ǔžnt, jtnox - 'ca:jtñx (Rmn), jfnoc - 'ža:jfnc (Med), jěnc $-s^{\prime}$ wẹ:jčnc (Med), jxnnt - 'ba:jxnt 'nehati'

$\mathbf{Z}+\mathbf{N}+\mathbf{N}+\mathbf{Z}$

$+\mathrm{m}_{\mathrm{o}} \quad \mathbf{r s t m}-$ 'porstm $(\mathrm{Omn}), \mathbf{j s t m}-$ sed'na:jstm

+n $\quad$ rščn $-\mathbf{L}$ 'turščn 'koruzen', jstno - 'yaijstn 'zavzet, prizadeven', jxtno 'fa:jxtn

$\mathbf{N}+\mathbf{Z}+\mathbf{N}+\mathbf{N}$

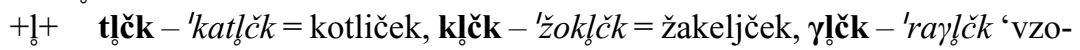
rec pri klekljanju'

$\mathbf{N}+\mathbf{N}+\mathbf{Z}+\mathbf{N}$

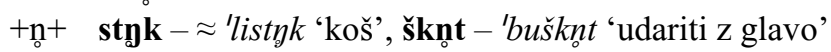

$\mathbf{Z}+\mathbf{Z}+\mathbf{N}+\mathbf{Z}+\mathbf{N}$

$+1+\mathbf{j} \mathbf{y} \gamma \mathbf{l} \mathbf{c}-{ }^{\prime} k a: j \eta \gamma l c(\mathrm{Med})$

+ no + jyknt $-c^{\prime}$ wẹ:jyknt 'klofutniti'

$\mathbf{Z}+\mathbf{Z}+\mathbf{N}+\mathbf{N}+\mathbf{Z}$

+ no + jnštñ $-' k u: j n s ̌ t n$

$+\mathrm{mo}^{+}$jnskm - pred'la:jnskm

\section{$3 \quad$ Medsamoglasniški sklopi}

Tudi med dvema samoglasnikoma lahko stoji največ štiridelni soglasniški sklop. Sklopi, ki v vzglasju ali izglasju ne nastopajo, so v preglednicah označeni z znakom $\oplus$.

\subsection{Dvodelni sklopi}

\subsection{1 $\mathrm{Z}+\mathrm{Z}$}

V medsamoglasniških sklopih lahko na prvem mestu stojijo vsi zvočniki, v narečju pa je (razen pri $w$ in $n$ ) možno tudi zaporedje dveh enakih zvočnikov. Sklop mr je bil zabeležen samo v prevzetih besedah.

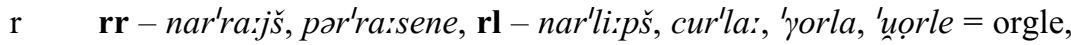

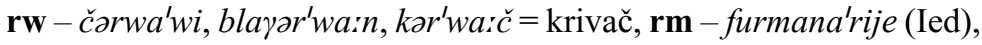
stər'ma:n 'strm', 'biẹrma, dor'warrma, rn - pərna'ša:l, čər'na:wa, 'marna = morna 'mlačna', ma'niẹrnu, rj - baldər'ja:n, der'ja: = dirjala, nar'jen, 'barječ

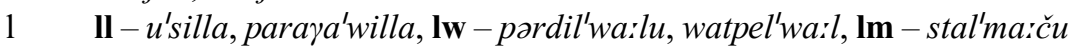
'raztolmačil', 'bulma = buljimo, 'muolma (sed. 3ed), ln - wal'nu: 'voljno', 'ilnata, 'ma:lna (Red), če'bulna, lj - mel'ja:rde, 'yulje (sed. 3ed), ba'tilje 'steklenica', ma'bilje 'pohištvo' 
u $\quad$ unr - zau're (sed. 3ed), 'do:urax (Med), 'sọiura = sora, ul - mrau'lie, paưlle:jcct, sk'riulen, wašlliulenu 'oslinjeno', ưm - 'a:umažna, 'na:üa 'ne bomo', un - barau'nic, bau'ni 'bolni', 'po:unem 'pomnim', unj deu'ja:čna, 'do:uje 'dolge', 'ka:uje, p'ra:uje

m mr-'cimraxa 'cimraka', 'ja:mra (sed. 3ed), 'ka:mra, ml - namla'tilu, pam'la:du, 'zemle, palluomlen, $\mathbf{m w}$ - naštim'wa:l, pasnem'wa:l, mm - 'nimma = nimamo, pa'luomma, mn - kam'nit, dam'nil 'domenili', 'somne 'semnja', mj - $\gamma^{\prime}$ romje 'grmovje', 'ka:mjon

n $\quad \mathbf{n m}$ - dlan'mi, 'a:nmu, 'koplenmu, $\mathbf{n w}$ - stan'wa:l, nj - '̌iẹnje (sed. $3 \mathrm{mn})$, be' $\gamma$ uonje, kala'fuonje

j $\quad \mathbf{j l}$ - 'mẹ:jle 'melje' (sed. 3ed), s'tẹ:jle, jm - buraj'miẹ 'vbogajme', 'de:jma = dajmo, 'li:skajmu = leskovemu, jn - braj'nie $=$ branje, mej'na: $^{\prime}$ (del. -l, ž ed), 'barajna = borovina, za'ba:jne, jw - naj'wuolna = neje-

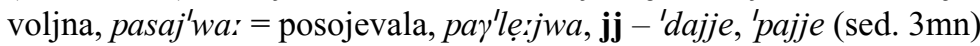

\begin{tabular}{|l|l|l|l|l|l|l|}
\hline & $\mathrm{r}$ & $\mathrm{l}$ & $\mathrm{w}$ & $\mathrm{m}$ & $\mathrm{n}$ & $\mathrm{j}$ \\
\hline $\mathrm{r}$ & $\oplus$ & + & $\oplus$ & $\oplus$ & $\oplus$ & $\oplus$ \\
\hline 1 & & $\oplus$ & $\oplus$ & $\oplus$ & $\oplus$ & $\oplus$ \\
\hline$\underline{\mathrm{u}}$ & + & + & & + & + & + \\
\hline $\mathrm{m}$ & + & + & $\oplus$ & $\oplus$ & $\oplus$ & + \\
\hline $\mathrm{n}$ & & & $\oplus$ & $\oplus$ & & + \\
\hline $\mathrm{j}$ & & + & $\oplus$ & + & + & $\oplus$ \\
\hline
\end{tabular}

\subsection{2 $N+N$}

$\mathrm{V}$ medsamoglasniški legi so zveze med pripornikom in zapornikom ter med dvema pripornikoma manj pogoste kot $\mathrm{v}$ vzglasju, zato pa se pomnožijo zveze preostalih dveh možnih povezav. $\gamma$ se ne pojavlja kot prvi člen sklopa. Zaporedja tf, sf, kk, ft nastopajo v izposojenkah.

p $\quad$ pt - wapte'sa:l, drap'tin, wallupta, ps - wapsa'dil, wap'si:če (sed. 3ed), 'ka:psau 'zeljnat', pš - wap'šitu, 'bapše = babišče, pk - wapka'suje,

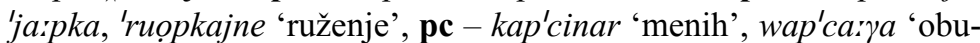
pa' (sed. 3ed), 'ba:pca, x'li:pci = hlebci, p̌ - wapču'dowat, klap'čina 'klobučevina', px - wapxa'dit, t'ri:pxa = trebuha

t tp - patpe'ra:l, watpa'čit, tt - wat'tesat, 'witta (sed. 2ed), 'siẹtte (vel. $2 \mathrm{mn}$ ), ts - wat'sapla, tk - patka'pa:l, patka'wa:č, 'uotka = otka, s'latka, tf - pret'fuọn 'pečica', tc - watcep'nil 'odpadli', 'ćitca = kitica, ka'ritce, tč - watčid'wa:l, s'latče 'sladke'

s $\quad \mathbf{s p}$ - raspar'tila 'razdelila', yaspa'darr, 'ispa 'podstrešje', st - presta'pit, ras'tur, 'la:stajce 'lastovice', 'mi:sta, ss - ras'si:kal, sk - wasku'bil, 'lisska = leska, 'piskaje (sed. 3mn), sf - wasfal'tiẹan, sc - us'ca:lu, 'missca = mesca, p'ra:sca (Red), š̌ - b'rus'čititne 'vrsta verige', sx - 'pa:sxa

s $\quad$ št - uštim'wa:l, paš'titt 'upoštevan', 'fušta 'butara', šp - zašpa'lit 'zašpiliti', krišs'puọt, 'kuošpa, 'pušpan, šk - flaš'kuon, waš'ku:pat, 'maški, 'piškau, š̌ - tarš'čie = trske, 'tešče = težke, p'ri:ščer 'kdor nabira prešce', šc - 'di:šca 'dežica', 'dušca, L k'rišscauka 'vzorec pri klekljanju' 
k kt - 'ča:kte, t'ra:ktar 'vozilo', ks - usak'sep, 'biksat, kk - 'cikk'line 'vrsta rezila', kc - sm'ri:kca

f ft -sklaf'tail, 'ca:ftat 'bos hoditi po blatu, vodi', 'jẹtalca 'kvačka', 'loft 'zrak'

c ct - de'wiẹctu 'devetsto' (prim. 3.2.5), cp - nac'pit 'nacepiti', ck wapac'ka:le, 'bucka, 'mucke

č ̌ck - s mačka:la, 'ka:čka 'kvačka', 'mičkan, čc - 'čečca 'deklica', $k^{\prime}$ ruọ̌ca 'vrsta motike', paj'tičce

x $\quad \mathbf{x t}-$ dax'ti:t, ne'wixta, p'la:xta, $\mathbf{x k}$ - mex'ki, 'laxka, $\mathbf{x c - w a x ' c u j j e , ~ ' l i : x c e ~}$ = lehice, $\check{s}^{\prime}$ waxcena, $\mathbf{x} \check{\mathbf{c}}-$ zmex'či $i$ (sed. 3ed)

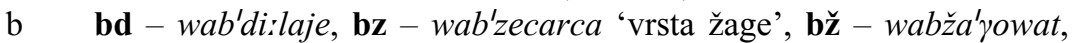

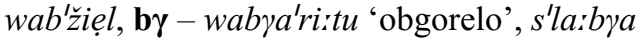

d $\quad \mathbf{d b}-$ wad'bila, dd - waddax'nilu, wad'di:lau, dz - wad'za:t, ď̌ -

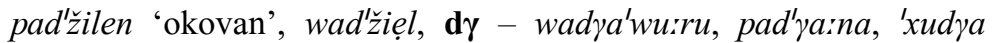
(Red)

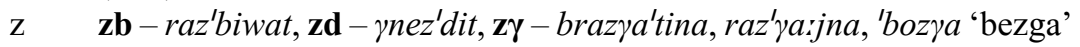
(Red)

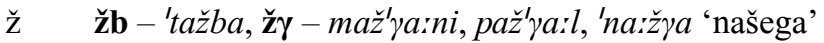

$3 \quad \mathbf{3} \gamma-w a z^{\prime} \gamma a r a, w a z \gamma u$ 'nilu 'odzvonilo'

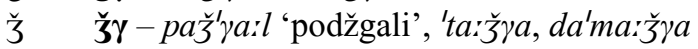

pripornik + zapornik

\begin{tabular}{|c|c|c|c|c|c|}
\hline & $\mathrm{b}$ & $\mathrm{p}$ & $\mathrm{d}$ & $\mathrm{t}$ & $\mathrm{k}$ \\
\hline $\mathrm{x}$ & & & & + & + \\
\hline $\mathrm{f}$ & & & & $\oplus$ & \\
\hline $\mathrm{s}$ & & + & & + & + \\
\hline$\check{\mathrm{s}}$ & & + & & + & + \\
\hline $\mathrm{z}$ & + & & + & & \\
\hline$\check{\mathrm{z}}$ & + & & & & \\
\hline
\end{tabular}

pripornik + pripornik

\begin{tabular}{|c|c|c|c|c|}
\hline & $\gamma$ & $\mathrm{x}$ & $\mathrm{f}$ & $\mathrm{s}$ \\
\hline $\mathrm{s}$ & & + & + & + \\
\hline $\mathrm{z}$ & + & & & \\
\hline $\mathrm{z}$ & + & & & \\
\hline
\end{tabular}

pripornik + zlitnik

\begin{tabular}{|c|c|c|}
\hline & $\mathrm{c}$ & $\check{\mathrm{c}}$ \\
\hline $\mathrm{x}$ & + & + \\
\hline $\mathrm{s}$ & + & + \\
\hline$\check{\mathrm{s}}$ & + & + \\
\hline
\end{tabular}


- zapornik + zapornik

\begin{tabular}{|c|c|c|c|c|c|}
\hline & $\mathrm{b}$ & $\mathrm{p}$ & $\mathrm{d}$ & $\mathrm{t}$ & $\mathrm{k}$ \\
\hline $\mathrm{b}$ & & & + & & \\
\hline $\mathrm{p}$ & & & & + & + \\
\hline $\mathrm{d}$ & $\oplus$ & & $\oplus$ & & \\
\hline $\mathrm{t}$ & & $\oplus$ & & + & + \\
\hline $\mathrm{k}$ & & & & + & $\oplus$ \\
\hline
\end{tabular}

zapornik + zlitnik

\begin{tabular}{|c|c|c|}
\hline & $\mathrm{c}$ & $\check{\mathrm{c}}$ \\
\hline $\mathrm{p}$ & + & + \\
\hline $\mathrm{t}$ & $\oplus$ & $\oplus$ \\
\hline $\mathrm{k}$ & $\oplus$ & \\
\hline
\end{tabular}

zlitnik + zapornik

\begin{tabular}{|c|c|c|c|c|c|}
\hline & $\mathrm{b}$ & $\mathrm{p}$ & $\mathrm{d}$ & $\mathrm{t}$ & $\mathrm{k}$ \\
\hline $\mathrm{c}$ & & + & & $\oplus$ & + \\
\hline$\check{c} \check{c}$ & & & & & + \\
\hline
\end{tabular}

zapornik + pripornik

\begin{tabular}{|c|c|c|c|c|c|c|c|}
\hline & $\gamma$ & $\mathrm{x}$ & $\mathrm{f}$ & $\mathrm{s}$ & $\breve{\mathrm{s}}$ & $\mathrm{z}$ & $\check{\mathrm{z}}$ \\
\hline $\mathrm{b}$ & $\oplus$ & & & & & $\oplus$ & $\oplus$ \\
\hline $\mathrm{p}$ & & + & & + & + & & \\
\hline $\mathrm{d}$ & $\oplus$ & & & & & $\oplus$ & $\oplus$ \\
\hline $\mathrm{t}$ & & & $\oplus$ & $\oplus$ & & & \\
\hline $\mathrm{k}$ & & & & + & & & \\
\hline
\end{tabular}

zlitnik + pripornik

\begin{tabular}{|c|c|}
\hline & $\gamma$ \\
\hline 3 & + \\
\hline $3 ̌ 3$ & $\oplus$ \\
\hline
\end{tabular}

zlitnik + zlitnik

\begin{tabular}{|l|l|}
\hline & $\mathrm{c}$ \\
\hline$\check{c}$ & + \\
\hline
\end{tabular}

\subsection{3 $\mathrm{N}+\mathrm{Z}$}

Čeprav je število možnih vzglasnih in medsamoglasniških sklopov dokaj izenačeno, je njihova razporeditev nekoliko drugačna. Med samoglasnikoma so namreč mogoče tudi zveze dveh glasov z večjo izgovorno bližino; pred $n$ lahko nastopajo vsi zvočniki, zveze z $j$ pa so še pogostejše. 
fn in cn sta sklopa prevzetih besed, fr pa se poleg tega pojavlja še v onomatopejah.

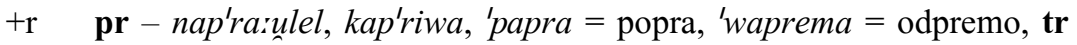
- patra'sil, katra'bant, 'fu:tra, 'jutre 'jutri', sr - nas'rẹjče, us'raijnše = usranišče 'umazane plenice', kr - pakra'piš, 'cukra (Red), 'makra, $\mathbf{f r}-$ caf'ra: $\check{s}=$ cefraš (sed. 2ed), kuf'riẹn 'bakren', 'cifra, cr - prec'ri:t = precvreti, wor'ciẹ 'vrvice', $\mathbf{x r}$ - waxra'nit, 'žixra 'lahko', 'worxast 'izbočen', br - nabru'sit, dab'ru:ta, 'čebra, 'čiẹbra = kebra (Red), dr nadra'bil, mad'ruọ, 'madras, zr - daz'ri:t, raz'ra:sla, waz'rọ:u 'ozrl',

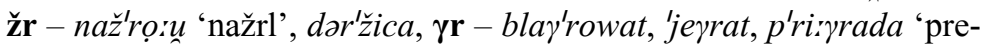
dal v skrinji za žito'

$+1 \quad$ pl - kap'la:t, 'dopla $=$ duplo, 'paplat $=$ podplat, tl - met'la: $(\mathrm{Rmn})$, 'katla (Red), 'metla, sl - nas'lanu 'naslonil', 'cisla, $\approx$ ma'rusle 'ošpice', šl - wašla'towau, 'ka:šle (sed. 3ed), 'tišler, kl - paklek'nil, 'ra:kle 'preklje', k'li:klel, fl - wafleu'ta:š 'popackaš', 'fufla 'zadnjica', 'šiefla, cl-jec'la: (sed. 3ed), z'ra:clen 'izrezljan', ̌̌l - 'puočla, u'rečla 'uročila', xl - paxla'dilu, 'puxla, za'tuoxlu, bl - z škab'luọn 'sirkova metlica za pomivanje posode', 'boblau 'bebljal', 'debla, dl - padla žil, 'cuodla 'cvetela', 'modla 'medla', zl - kazla'wiše, 'li:zla (del. -l, ž ed), žl -

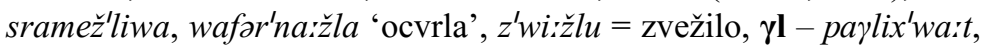

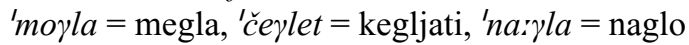

${ }^{+} \mathbf{w} \quad \mathbf{p w}-k_{u} p^{\prime} w a: l, n a k a p^{\prime} w a: l$ 'nakopavali', tw - klet'win, rat'wa:le, 'li:twa 'dleto', 'siẹtwa 'setev', šw - spraš'wa:t, preš'wican, paswe'na: (del. -l, ž ed), sw - 'niswa, 'nuọwa, $\mathbf{k w}$ - pak'wiẹcen, 'bukwa, $\mathbf{c w}$ - wac'wiẹk, wac'wibe 'rozine', ̌̌w - plač'wa:l, wabeč'wa:l 'obljubljali', $\mathbf{x w ~ - ~}$

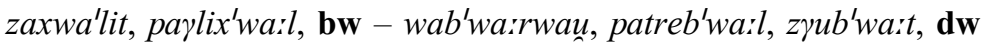
- med'wẹ:jka 'ivanjščica', wad'wiwat 'odvijati', k'la:dwa, ka'liẹdwat, $\mathbf{z W}-$ pawez'wa:l, wam'li:zwa = omlezva, $\mathbf{z} \mathbf{w}-$ daž'wi:t, maž'wa:l, $\boldsymbol{\gamma} \mathbf{w}-$ nate $\gamma^{\prime}$ wa:t, pre $\gamma^{\prime}$ wiẹra 'se ohrani'

$+\mathrm{m} \quad \mathbf{t m}$ - pat'mi (Omn), m'la:tma, 'usnatmu, sm - zasma'dila, čes'min, kas'ma:čka, šm - uš'mi, 'wa:šmu 'vašemu', k'li:šman 'kleščman', km 'ta:kmu, čm - 'ječmen, 'rečma (sed. 1mn), wačmi (Omn), xm-zax'ma:šñ , bm - zab'mi (Omn), 'ra:bma, dm - 'sedma, wadma'čle, pad'mest, $\mathbf{z m ~ - ~}$ uz'mite 'vzemite', kate'kizma, žm - 'čižma, pad'wižma 'podvizajmo'

$+\mathrm{n} \quad$ pn - ap'niẹn, 'napne, štapne 'stopinja', tn - plat'nien, dewet'na:jst, 'čitnam = ketnjami (Omn), sn - pasnem'wa:l, kas'nica $=$ kostnica, 'masnu = mastno, šn - paš'nuofa, plaš'na:ta = ploščnata, 'či:šne, kn luk'niẹ = luknje, 'žokna = žekno, 'cukne (sed. 3ed), fn - k'lafnu, cn 'locna (Red), 'nuсnu, čn - 'la: čna, 'načneš, zwez'da: ̌̌nu 'zvezdnato', xn

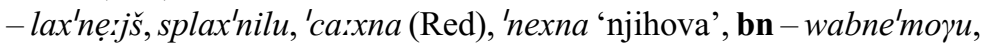
drab'na:k, 'ba:bna 'babina', 'cobne, dn - 'za:dna, na'ruodnu, ad'na:jst 'enajst', pad'ne:ij 'podnevi', zn - pawez'nilu, waz'nik, waz'nu:tər 'od-

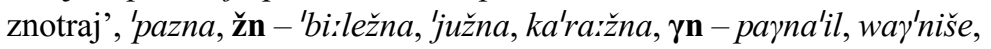

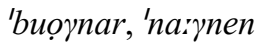


$+\mathrm{j} \quad \mathbf{p j}-$ up'ja:nl, 'ci:pje, 'kupje (sed. 3mn), tj - snežet'juo (Oed), b'ra:tje, 'čutje, s'puotje, sj - nas'ja:l, 'kuosje 'kosišče', 'nuosje (sed. 3mn), čj nač́juo (Oed), 'ka:čje, ba'dičcje, šj - 'mišje (Oed), bj - wab'jeskat = obiskati, 'lubje, 'worbje, dj - pred'južnk, 'sa:dje, 'widje, z'lu:dje = zlodja, zj - b'ri:zje, 'uozje (sed. 3mn), žj - baž'ja:st, 'bažje, s'tuožje

\begin{tabular}{|l|l|l|l|l|l|l|}
\hline & $\mathrm{r}$ & 1 & $\mathrm{w}$ & $\mathrm{m}$ & $\mathrm{n}$ & $\mathrm{j}$ \\
\hline $\mathrm{p}$ & + & + & $\oplus$ & & $\oplus$ & + \\
\hline $\mathrm{b}$ & + & + & $\oplus$ & $\oplus$ & $\oplus$ & $\oplus$ \\
\hline $\mathrm{f}$ & + & + & & & $\oplus$ & \\
\hline $\mathrm{t}$ & + & + & $\oplus$ & + & + & $\oplus$ \\
\hline $\mathrm{d}$ & + & + & + & + & + & + \\
\hline $\mathrm{s}$ & + & + & + & + & + & + \\
\hline $\mathrm{z}$ & + & + & + & + & + & + \\
\hline $\mathrm{c}$ & + & $\oplus$ & + & & + & \\
\hline$\check{\mathrm{s}}$ & & + & + & + & + & $\oplus$ \\
\hline$\check{\mathrm{z}}$ & + & + & + & + & + & $\oplus$ \\
\hline$\check{\mathrm{c}}$ & & + & + & + & $\oplus$ & $\oplus$ \\
\hline $\mathrm{k}$ & + & + & + & + & + & \\
\hline$\gamma$ & + & + & + & & + & \\
\hline $\mathrm{x}$ & + & + & + & + & + & \\
\hline
\end{tabular}

\subsubsection{Z + N}

Če izvzamemo zveze z zvenečimi nezvočniki, pri katerih se le $b$ ne pojavlja za $n, \check{z}$ in $z$ pa ne za $l$ in $n$ ter $m$ (z enim samim primerom za m̌̌), je v izglasju možnih celo nekoliko več povezav. Sklopi lb, lf, rt, $\mathbf{m f}, \mathbf{m b}, \mathbf{m} \check{z}, \mathbf{n f}, \mathbf{y} \gamma, \mathbf{u} \mathbf{f}$,

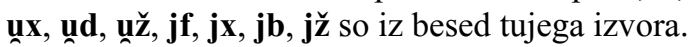

r $\quad \mathbf{r p}$ - parp'e:jle, star'piẹn, 'šerpa 'volneno ogrinjalo', 'torpu $=$ trpel, rt - 'biẹrtax, 'pa:rtar 'kdor ima pravico do paše na skupnem pašniku', rs - 'darsal, rš - zүar'šit, 'buorša, 'karšen = krščen, rk - cork'la:jnsk, 'ciẹrku, 'šurkauc = ščurkovec 'vrsta fižola', rc 'fa:jerca 'vžigalica', 'maštarce = moštarice 'vrsta hrušk', 'fiẹrcat $=$ firbcati, ř̌ - pər'ča:kal, wac'wiẹrče = ocvirke (Tmn), s'pa:rčen 'razdeljen', rx - stor'xa:r, rb - 'čiẹr'bot = kjerbodi 'kjer koli', mar'bet $=$ morebiti, 'wiẹrbas, 'worba, rd - barda'wica, žardi'niẹra 'kočija', 'torda, rz - wabrr'zowat, 'biẹrza, ř̌ - 'doržat, 'uržax, s'təržema

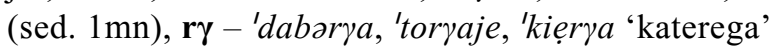

1 It - 'jelte, 'muolte, lš - de'biẹlša 'debelejša', z'bu:lšal, lk - 'bilka, $\approx$ 'celkna 'šotorsko krilo', 'ku:lki 'kolikaj', lf - yal'fa:t, lc - u'vonalca 'uganka', lč - 'bulčast 'bulast', 'pa:lčejna 'pajčevina', lb - 'wiẹlban, $\mathbf{l d}$ - yul'dinar, 'jelde, 'meldat 'prijaviti', $\mathbf{l} \boldsymbol{\gamma}$ - 'bi:lya, 'yalya (Red)

u $\quad$ up - zau'pe:ı 'zavpil', 'zo:uprna, ut - fleu'ta: 'packa' (sed. 3ed), sau'ta:le 'čvekale', 'la:utast 'jezikav', 'ma:uta 'blato, malta', unš -

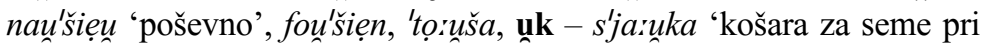


sejanju', ši'wa:ukka 'šivanka', 'čiukaje, ưf - 'la:ufar, unc - 'auca, 'ko:ucat,

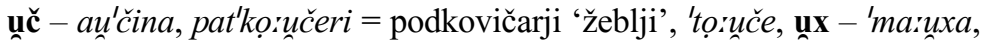
Pd p'ra:uxat 'opravljati', unb - 'do:ube, 'lo:uber = lovor, und - 'ba:uda, 'jọ:uda 'stoka', 'žo:udarce 'dninarice', uzz - preúziłnu = prevzdignil

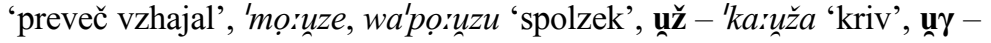

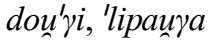

m $\mathbf{m t}-$ 'luomta, u'zomta $=$ vzemita, $\mathbf{m} \mathbf{f}-\approx$ kam'fin 'mejnik', 'šimfat, mc - 'ja:mca, s'la:mca 'pehar', wab'ra:mce = obramnice 'naramnice', mb - Z bam'ba:ža, kam'ba:ča 'vedra' (Red), md - zam'dila = zamudila,

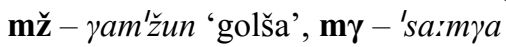

n nt - kante'nina, an'tu:lku, 'cunta 'cunja', 'dente 'denite', $\mathbf{n f}-\approx$ kan'fin, nc - pa kan'ci:x, pan'ceta, 'ma:jenca 'ličkanje', nč - bren'či, lan'čiẹn,

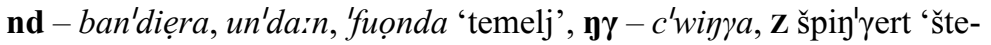
dilnik', 'ma:layra (m Red)

j jt - 'ba:jta, 'ča:jte 'čakajte', rej'ta:jne 'kar gre skozi reto', js - 'pe:jsa 'pesa', 'pa:jsat, wa'bẹ:jsenu 'obešeno', jš - k'ra:jšet, 'siẹrkajše 'koruzišče', jk - 'za:jka, med'wẹ:jka, wa'ma:jkau = omajkov 'olupkov' (Rmn),

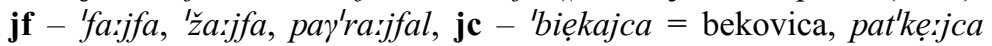
'podkev', 'jaijce, jč - 'nẹijče 'noče', wa'maijče 'olupke' (Tmn), wabej'čujem, jx - 'ca:jxast, jb - 'ajbeš, 'ša:jba, t'ra:jbal 'vlačili', jd - 'na:jdem, 'ra:jda, z'na:jden, jz - pa'wẹ:jzau 'povezal', jžz - 'ra:jža,

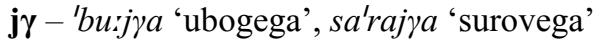

\begin{tabular}{|c|c|c|c|c|c|c|c|c|c|c|c|c|c|c|}
\hline & $\mathrm{p}$ & $\mathrm{b}$ & $\mathrm{f}$ & $\mathrm{t}$ & $\mathrm{d}$ & $\mathrm{s}$ & $\mathrm{z}$ & $\mathrm{c}$ & $\check{\mathrm{s}}$ & $\check{\mathrm{z}}$ & $\check{\mathrm{c}}$ & $\mathrm{k}$ & $\gamma$ & $\mathrm{x}$ \\
\hline $\mathrm{r}$ & + & $\oplus$ & & + & $\oplus$ & + & $\oplus$ & + & + & $\oplus$ & + & + & $\oplus$ & + \\
\hline $\mathrm{l}$ & & + & + & + & $\oplus$ & & & + & + & & + & + & $\oplus$ & \\
\hline $\mathrm{u}$ & + & + & $\oplus$ & + & + & & + & + & + & + & + & + & + & + \\
\hline $\mathrm{m}$ & & $\oplus$ & + & $\oplus$ & $\oplus$ & & & + & & $\oplus$ & & & $\oplus$ & \\
\hline $\mathrm{n}$ & & & $\oplus$ & + & $\oplus$ & & & + & & & + & & $\oplus$ & \\
\hline $\mathrm{j}$ & & $\oplus$ & + & + & $\oplus$ & + & $\oplus$ & + & + & $\oplus$ & + & + & $\oplus$ & + \\
\hline
\end{tabular}

\subsection{Tridelni sklopi}

$\mathrm{V}$ gradivu ni zaporedij $\mathrm{N}+\mathrm{Z}+\mathrm{N}$ (ki je sicer redko tudi v knjižnem jeziku) in $\mathrm{N}+\mathrm{Z}+\mathrm{Z}$ (Srebot-Rejec 1975a: 41-42). Prim. 3.2.8.

\subsection{1 $Z+Z+Z$}

Zveze treh zvočnikov med dvema samoglasnikoma so izjemne. T. SrebotRejec (1975a: 45) za knjižni jezik navaja 19 sklopov te vrste.

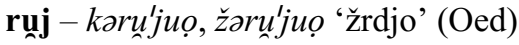

$$
\begin{aligned}
& \text { unml - 'po:umlat }
\end{aligned}
$$

(2) $+1+$ mln - 'ri:mlni

$+\mathrm{n}+\mathbf{r n o m}-$ '̌́ว 
3.2.2 $\mathrm{Z}+\mathrm{N}+\mathrm{Z}$

Najpogostejši so sklopi z začetnim $r$ ali $j$, medtem ko so zveze $z l$ in $m$ izjemne.

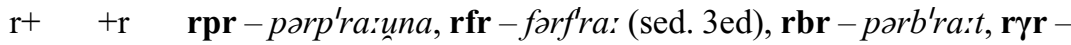
pary'reben

+1 rpl-parp'lu 'prihitel', ršl-boršlla:n, morš'lin 'muslin', 'poršla, rkl - 'burkle, 'pa:rkla (Red), rxl - parxla'dila, starxle'ni:lu, 'korxle, rdl - smord'liuc 'petrolej', rzl - morz'lu', ryl-pory'lixa 'primerjava', 'woryla

+m $\quad$ rsm - pars'majenu, ržm - bərž'ma: $\gamma a t$ 'biti užaljen zaradi neprimernosti česa'

$+\mathrm{n} \quad \mathbf{r t n}$ - čekart'nica 'četrtnica', rsn - kars'nica, ršn - 'ku:kəršna, 'məršna 'mrha', rkn - c'warknu (del. -l, m ed), rcn - 'karcnu, rčn - 'fiẹrčna 'radovedna', 'lizzerčna 'plazilci, kače', rzn -

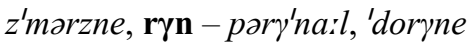

+w rtw - mort'wa:šk, 'mortwix, rkw - zamerk'wa: 'spominjala' (del. -l, ž ed), 'ciẹrkwe (Red), rčw - narč'wa:t, rzw - zmorz'wa: (del. $-l$, ž ed)

$+\mathrm{j} \quad \mathbf{r s ̌ j}-{ }^{\prime}$ taršje, $\mathbf{r c j}-$ terc'ja:lke (Imn)

$1+\quad+\mathrm{w} \quad \mathbf{l d w}-{ }^{\prime}$ teld'wi: 'tidve'

$+\mathbf{r} \quad \mathbf{l k r}-k u l k^{\prime} r a t^{\prime}$

unt+ +r upr - poup'riẹč 'povprek', 'co:uprat, untr - 'ko:utratra (Red), uيndr 'po:'ud'ruj 'poldrug'

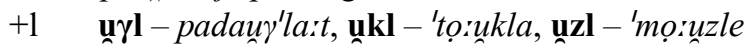

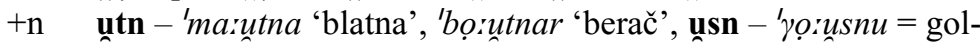
snil, 'ka:unsna 'slabo vino', ưšn - 'ri:ušna, unkn - 'pi:ukne 'pevka', 'či:uknem, unčn - naka'pa:ǔčne 'kopačica', sa'diučne 'sadilka', yrab'liučne 'grabljica', undn - 'po:udne, uxxn - 'po:uxna 'polna', ưzn - 'sọ:uzna, s'po:'uznu (del.-l, m ed), unžn - 'dọ:ǔ̃žna

$+\mathrm{j} \quad \mathbf{u}$ šj - 'uọušjje 'jelševje'

$\mathrm{m}+\quad+1 \quad \mathbf{m p l}-$ kamp'lena 'končana'

$+\mathrm{r} \quad \mathbf{m p r}-{ }^{\prime}$ cimpra $(\mathrm{Red})$

$\mathrm{n}+\quad+1 \quad \mathbf{g k l}$ - 'bigkle, $\mathbf{n c l}-$ wakranc'la:l, ndl - 'a:ndla 'ravna' (sed. 3ed)

$+\mathbf{r} \quad \mathbf{n t r}$ - 'aintrex 'obrt', ndr - mand'raije 'mendrajo', 'sundra (Red), $\mathbf{y} \gamma \mathbf{r}-$ 'figyrat

$+\mathrm{n} \quad \mathbf{\eta k n}-$ ufleyknen 'prismojen'

+w $\quad \mathbf{n t w}$ - fant'wa:l, 'lintwern 'zmaj', $\mathbf{n k w}$ - činkwan'tin

$+\mathrm{j} \quad \mathbf{n t j}-\check{s}$ ent'ja:jnžewe, 'fa:ntje, ndw - wand'wi: 'onidve'

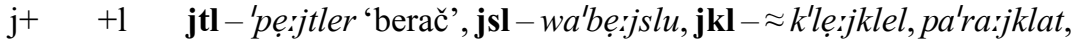
jdl - 'na:jdla, jžl - ' 'a:jžla

$+\mathrm{r} \quad \mathbf{j k r}-\approx$ kajk'ra:t 'večkrat', jtr - 'ya:jtraš, 'lu:jtre

$+\mathrm{m} \quad \mathbf{j s m}-$ wa'bẹjsma (vel., 2mn), jžm - 'bẹ:jžma

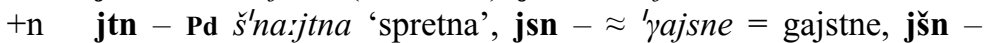
'fa:ntajšna 'fantovščina', sa'sẹ:jšna = soseščina, jčn - s'rẹ:jčnu, jxn - 'ba:jxnu 'nehal', jdn - 'la:jdnauc 'gnoj iz človeških iztrebkov', s'rẹijdne 


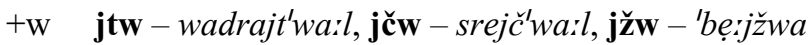

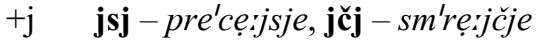

\subsection{3 $\mathrm{Z}+\mathrm{N}+\mathrm{N}$}

Zveze $\mathrm{z}$ začetnim $r$ predstavljajo več kot tretjino $\mathrm{z}$ gradivom potrjenih sklopov. Zvočniku le izjemoma sledita dva zveneča nezvočnika. Zveza med pripornikom in zapornikom daleč prekaša število drugih možnih povezav.

$\mathrm{r} \quad+\mathrm{p} \quad$ rps - parps'til

$+\mathrm{t} \quad \mathbf{r t k}$ - 'bartka, rtx - L 'bi:rtxe 'predpasnike' (Tmn)

$+\mathrm{r} \quad \mathbf{r s t}$ - bars'tene, kars'til, 'porste (Tmn), rsk-mars'kešn 'marsikakšen', 'torska

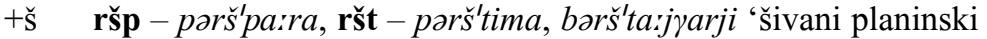
čevlji', ršč - tarš'čie = trske, ršc - 'suoršca $=$ soržica

$+\check{c} \quad$ rčk-m'xu:rčkau (Rmn)

$+\mathrm{z} \quad \mathbf{r z} \gamma-$ prrz $^{\prime}$ oowau $=$ privzdigoval

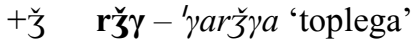

$1+$ s $\quad$ lsk - 'šurlske

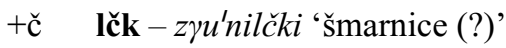

$+\check{z} \quad \mathbf{l z ̌} \gamma-{ }^{\prime} b u: l z ̌ \gamma a$

u $\quad+\mathbf{s} \quad$ unsk $-s^{\prime}$ po: unsku, unst - 'to:usta

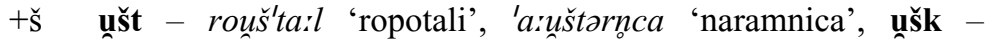
'di:cauška 'moška', uيňsc - 'bi:ư⿱šca 'prvo žganje'

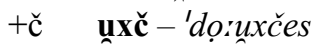

$\mathrm{m}+\mathrm{s}$ msk $-{ }^{\prime}$ zimske

$+\check{\mathbf{s}} \quad \mathbf{m s ̌ k}-{ }^{\prime}$ ni:mška

+ č mčk-'ka:mčki 'kamenčki'

$\mathrm{n} \quad+\mathrm{s} \quad \mathbf{n s t}-{ }^{\prime}$ tiẹnstal

+ č nčk-'ta:nčkawa 'grahova'

j $\quad+\mathbf{s} \quad \mathbf{j s k}-{ }^{\prime} w a j s k a$

$+\check{\mathbf{s}} \quad \mathbf{j s ̌ t}$ - 'la:jšta, 'bẹ:jšte, ǰšc - pa'bu:jšcau 'pobožal', ǰšc - 'wajšče 'vojske', $z$ 'na:jščem 'nožem'

$+\check{c} \quad \mathbf{j c ̌ k}-$ 'jẹjjčkau $(\mathrm{Rmn})$

$+\mathrm{z} \quad \mathbf{j z} \boldsymbol{\gamma}-d^{\prime} w a: j z \gamma a$

\subsection{4 $\mathbf{N}+\mathbf{N}+\mathbf{Z}$}

Dva nezvočnika se najpogosteje vežeta $\mathrm{z} r$. Zveza dveh pripornikov $\mathrm{z}$ zvočnikom je izjemna.

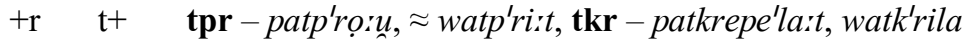

$\mathrm{s}^{+} \quad \mathbf{s p r}$ - paspraúla:l, nasp'ruitn, str - wastra'šil, 'sestra, 'wastra 'ostra', skr - usk'ril 'skrili', dask'ra:t 'dostikrat', 'piskri

š+ $\quad$ špr - pašp'rical, štr - kašt'ruọn, zbešt'ra:n 'zbujen', 'fa:jmaštru (Ded), škr - paškra'pila

$\mathrm{f}+\mathbf{f t r}-k^{\prime} l a: f t r a$

č+ $\quad$ čkr - wečk'ra:t

b+ $\quad \mathbf{b} \gamma \mathbf{r}-w a b \gamma^{\prime}$ riẹncat 'oglodati' 
d+ $\quad \mathbf{d b r}-$ padb'ra:tk, wadb'ra:na (sed. 3ed), d $\gamma \mathbf{r}$ - pady'riwke 'neke ptice'

$\mathrm{z}^{+} \quad \mathbf{z d r}-\approx$ pazd'ra:jla 'pozdravila'

$+1 \quad \mathrm{p}^{+} \quad \mathbf{p s ̌ l}-$ wapš'li:sana, $\mathbf{p k l}-$ wapkla'da:l

t+ $\quad$ tpl - patpla:ta, $\mathbf{t s l}$ - watslu'žit, tkl - watk'la:umfau

$\mathrm{s}^{+} \quad \mathbf{s p l}-$ rasp'lut 'raztopiti v vodi', $\mathbf{s k l}-\approx$ ma'ruskle 'ošpice'

$\mathrm{k}+\mathbf{k s}-d^{\prime}$ ra:kslet

$+\mathrm{w} \quad \mathrm{p}^{+} \quad \mathbf{p c ̌ w}-k a p c ̌ w a: l$

$\mathrm{t}+\quad \mathbf{t k w}-u t k^{\prime}$ wa:t 'vtikovati'

s+ $\quad$ stw - yast'wa:l, 'pisstwa 'pestuje', ba'yaistwa, skw - b'riskwa

š+ $\quad$ štw - 'bu:štwa 'revščina'

$\mathrm{k}+\quad \mathbf{k s ̌ w}-$ fukš'wanc 'vrsta žage'

$\mathrm{x}+\quad \mathbf{x p w}-\mathbf{L}$ uxp'wa:le 'kupovale'

$\mathrm{z}^{+} \quad \mathbf{z} \boldsymbol{\gamma} \mathbf{w}-u z \gamma^{\prime} w a: l$

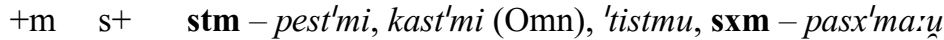

$+\mathrm{n} \quad \mathrm{p}+$ pěn - 'yipčna

t+ $\mathbf{t k n}$ - datk'nit 'dotakniti'

$\mathrm{s}^{+} \quad$ stn - parast'nilu 'zgostilo', 'cisstnu, 'korstna

š $+\quad$ škn - 'bušknem

k+ $\quad \mathbf{k s ̌ n}-\mathbf{B}-\mathbf{L}$ dər'ya:kšne 'drugačne'

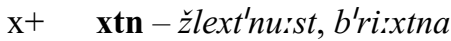

b+ $\quad$ bzn $-k a b z ' n i k=$ kapusnik/kapuznik 'zeljnik'

$\mathrm{d}+\quad \mathbf{d} \gamma \mathbf{n}-$ wad $\gamma^{\prime} n a: l$

$+\mathrm{j} \quad \mathrm{s}+\quad \mathbf{s t j}-{ }^{\prime}$ 'istje, slast'juo, 'kurstje = kostjo (Oed)

$\mathrm{x}^{+} \quad \mathbf{x c j}-$ waxc $^{+} \mathrm{juo}(\mathrm{Oed})$

$\mathrm{z}^{+} \quad \mathbf{z d j}-\gamma^{\prime}$ ruozdje

\subsection{5 $\mathrm{N}+\mathrm{N}+\mathrm{N}$}

Zveze treh nezvočnikov so $\mathrm{v}$ nasprotju s knjižnim jezikom (Srebot-Rejec 1975a: 35) zelo redke. Pri tistih $\mathrm{s} t$ kot prvim členom je na tem mestu mogoč tudi izgovor zlitnikov, vendar je pri večini govorcev zaporni del še ločen od pripornega (ni slušnega vtisa o enotnosti glasu).

$\mathrm{p}^{+} \quad \mathbf{p s t}-$ waps'ta:lu, $\mathbf{p s k}-x^{\prime}$ ripska, pčk $-d^{\prime}$ 'rapčkan

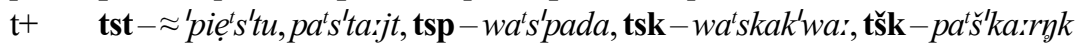

$\mathrm{z}^{+} \quad \mathbf{z d} \gamma-{ }^{\prime} \gamma u o z d \gamma a$ 'gostega'

\subsection{6 $\mathbf{Z}+\mathbf{Z}+\mathbf{N}$}

(1) Med sklope spadajo tričlenske zveze z začetnim $j+n$ ter $u+m$. Nabora sklopov v knjižnem jeziku in narečju se ne prekrivata (Srebot-Rejec 1975a: 45-46).

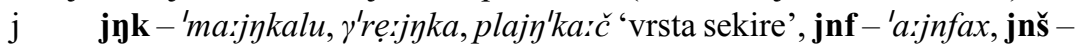
us'ra:jnše = usranišče, jnc - da'le:jnca 'spodnje krilo', 'ra:jnca 'rajnica', jnč - 'tẹ:jnče 'tenke' (Imn), jnž - šta:jnže 'štange', šent'ja:jnžewe,

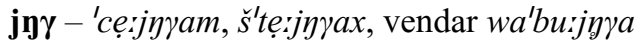

u $\quad$ ump - PI 'ro:umpa 'poseben prostor v kleti za shranjevanje pepela',

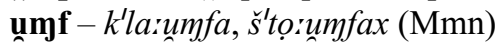


(2) V drugih primerih gre za zveze z zlogotvornim zvočnikom ( $($ o oz. $!$ ):

$+1+$ rloc $-{ }^{\prime}$ torlca, ${ }^{\prime} \gamma \partial r l c a$

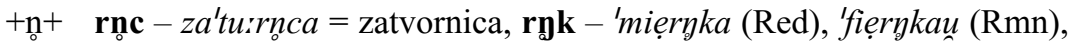

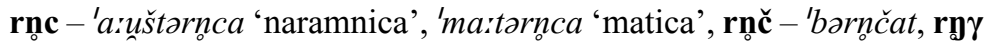

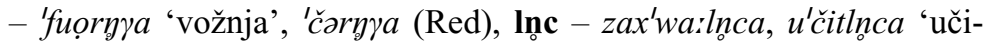

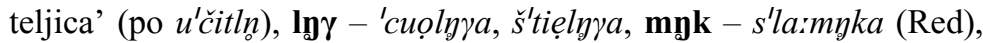
$\mathbf{m g} \gamma-$ wa'zimgra (Red), ungk - 'widaungki = vedovniki 'vedomci', 'ma:saunkam = maslovnikom (Oed), unnc - 'puodaunce 'pečnice',

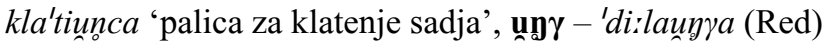

3.2.7 Druge zveze z zlogotvornimi zvočniki

$\mathbf{N}+\mathbf{Z}+\mathbf{Z}$

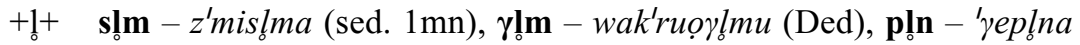
(Red), ț̊n - 'butlına (del. -l, ž ed), u'čitlına (Red), sı̊n - 'mislna, pa'tislgna (del. -l, ž ed), kḷn - k'li:klne = klekeljne (Tmn), 'ciklnu 'postalo kislo' (del. -l, s ed), 'kuoklna (Red), fḷn - 'ta:flni 'vrsta jabolk', cḷn - 'loclnam 'ročajem' (Oed), dḷn - k'niẹdlni, xlın - 'ma:xlne (del. -l, ž $\mathrm{mn}), \gamma \mathbf{l n}$ - 'na: $\gamma l n e(\mathrm{Tmn}), d^{\prime} w i \gamma l n u, k^{\prime} r i \gamma l n a(\mathrm{Red}), \mathbf{k l} \mathbf{w}$ - wakl'wa:le (del. $-l$, ž mn)

$+\mathrm{mog}^{+} \mathbf{s m n}-$ wasm'na:jzya

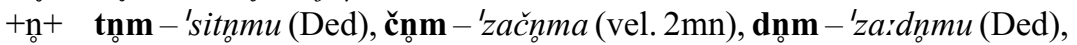

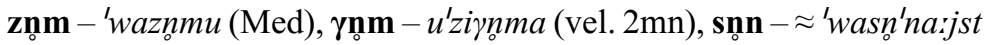
'osemnajst', dnon - $\approx$ 'sedñ'na:jst 'sedemnajst', znow - prazn'wa:l

$\mathbf{N}+\mathbf{Z}+\mathbf{N}$

$+1+\quad$ pls - zapl'sa:t = zaplesati', plx - 'duoplaxar 'dvojni plug, kozolec', țc - par'ja:tlca, slp - wasl’pi:t = oslepeti, șac - 'cislca 'kislica', p'riẹslca, $\mathbf{s l} \gamma$ - 'cislya 'kislega' (Red), s̆lı - 'pušllce (Tmn), klıc - 'di:klıa, 'ra:klca 'prekljica', f'ra:klce (Tmn), flıc - k'nuoflca 'bucika', flıč - 'kiflčer 'vrsta fižola, krompirja', blı̆ $-\gamma^{\prime}$ ra:blšse = grabljišče, bolc - 'šublca 'lopatica', 'ta:blce, bld - wabl'di:ta 'obledela', dlı - idl'ba:js 'planika', dı̊s - wadl'šila = odluščila, dlıc - 'la:dlcu (Med), dl $\gamma$ - 'modl $\gamma a=$ medlega

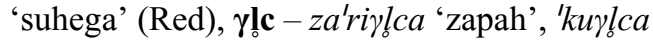

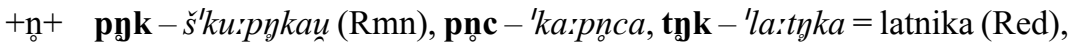

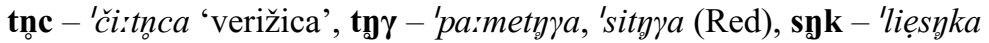
$=$ lesnika, snc $-\approx p a$ 'ku:snca 'gostija po košnji', wab'risnca 'cunja za

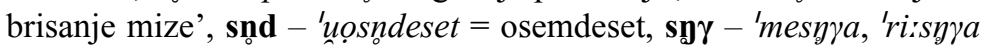
(Red), šnk - 'pa:šyke, st'ri:šgke (Tmn), šnc - L pa'ku:šnca, st'ri:šnca

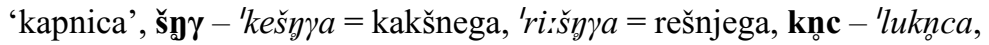
čnk - 'fičnke (Tmn), čnc - šu'ničnca 'vrsta hruške', pad'ruọ̌nca 'ple-

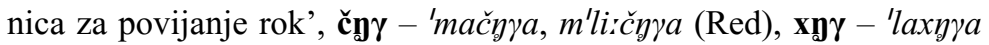
(Red), byk - 'ba:bykar 'babjak', bnc - 'ba:bnca, d'ruobnca, by $\gamma-$

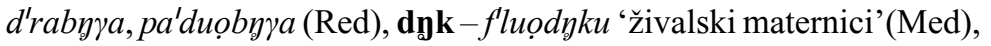

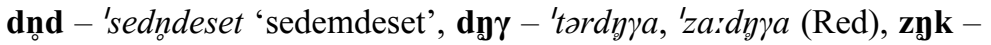

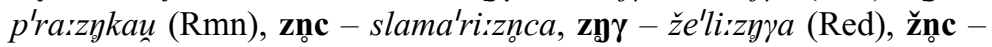

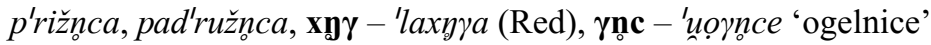




\section{3 Štiridelni sklopi}

Prvi člen sklopa je najpogosteje $j$, če sklop začenjata dva zvočnika, pa $j$ $+n$. V narečju ni sklopov $\mathrm{N}+\mathrm{N}+\mathrm{Z}+\mathrm{Z}$ in $\mathrm{N}+\mathrm{Z}+\mathrm{Z}+\mathrm{Z}$ (Srebot-Rejec 1975a: 51).

\subsection{1 $\mathbf{Z}+\mathbf{N}+\mathbf{N}+\mathbf{Z}$}

r $\quad$ rpšn - 'wiẹrpšna 'dediščina', rščn $-\mathbf{L}-\mathbf{s}$ 'turščna 'koruzna'

un ustr - aust'risk, unštr - 'po: us štra (Red)

n nstw - raspa'dinstwa (Ied)

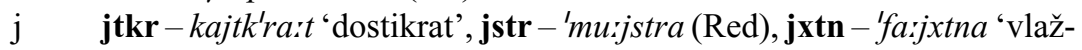
na', jštw - 'pa:jštwa 'sušilnica za sadje', jškr - 'mu:jškra

\subsection{2 $\mathbf{Z}+\mathbf{N}+\mathbf{N}+\mathbf{N}$}

r rpst - porp'sti

u $\quad$ unzd $\gamma-{ }^{\prime}$ tọ:uzd $\gamma a($ Red)

\subsection{3 $\mathbf{Z}+\mathbf{Z}+\mathbf{N}+\mathbf{N}$}

Zaporedje soglasnikov v teh sklopih je značilno narečno (prim. Srebot-Rejec 1975a: 53).

(1) j jlsk - ne'dẹ:jlski (Imn), jnsk - 'la:jnsku, '̌̌ẹjnske, ca'ya:jnsku, jnsc - šta:jnsca 'pletilka', jnčk - 'kuojnčka (Red), ka'me:jnčkal, jnž

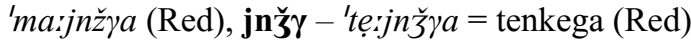

(2) $+{ }_{\mathrm{m}}+$ rmočk - 'ja:rmock $a$

+ no+ rngzy - mle'ka:rnzya

3.3.4 $\mathbf{Z}+\mathbf{Z}+\mathbf{N}+\mathbf{Z}$

(1) u u umpr $-\mathbf{L}$ 'cọ:umpram 'čaram'

j $\quad \mathbf{j n s ̌ w}-$ zmajnš'wa: (del. -l, ž ed), jnkl - 'pu:jpkle (Tmn), jykw majpk'wa:lu 'primanjkovalo', jnčm - pa 'tẹ:jnčmu = tenkemu, jn $\gamma \mathbf{l}-$ 'ka:jypla

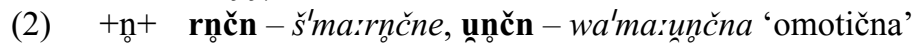

\subsection{5 $\mathbf{N}+\mathbf{N}+\mathbf{N}+\mathbf{Z}$}

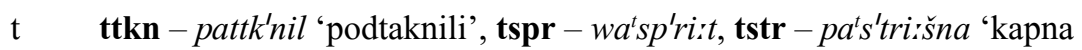
lega'

3.3.6 Zveze z zlogotvornimi zvočniki:

Sklopov mp, nk in nz ni med običajnimi medsamoglasniškimi.

$\mathbf{Z}+\mathbf{N}+\mathbf{Z}+\mathbf{N}$

$+1+\quad \mathbf{y} \gamma \mathbf{l} \mathbf{n}-$ 'rim

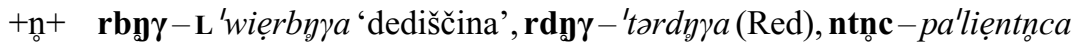
'žgančevka', nčnce - pa'su:nčnce 'sončnice', untgk - 'ka:utgka 'pregoste

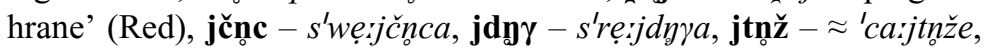

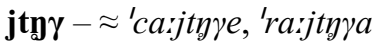


$\mathbf{N}+\mathbf{Z}+\mathbf{N}+\mathbf{Z}$

$+\mathrm{m}_{\mathrm{o}}+\mathbf{d m k n}-$ spadmk'nilu $^{\prime}$

$+{ }_{0}+$ tnodw - 'piẹtndd'wa:jst, $\mathbf{z} \mathbf{g} \mathbf{k r}-{ }^{\prime}$ 'rožngk'ra:unta

$\mathbf{N}+\mathbf{Z}+\mathbf{N}+\mathbf{N}$

$+1+\mathbf{k} \mathbf{l} \mathbf{s t}-$ wakls'til

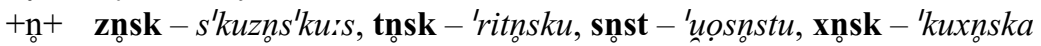

$\mathbf{Z}+\mathbf{N}+\mathbf{Z}+\mathbf{Z}$

+lo ršln - pe'toršlna (Red), rklon - 'puorklne 'naoknice' (Tmn), 'corklna,

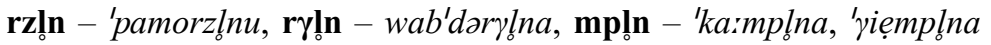
'kalina' (Red), ntlın - 'muọtlona (Red), nklon - 'šigklni 'skodle', štrr'pa:yklni 'podveze', nclon - 'fa:nclnax 'flancatih' (Mmn), b'riẹnclna

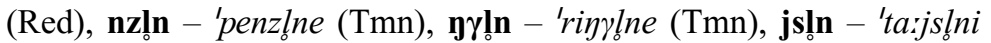
'furmanski vozovi', jdlın - rajs'na:jdlne 'risalne žebljičke'

$\mathbf{N}+\mathbf{N}+\mathbf{Z}+\mathbf{Z}$

$+1+\quad$ šklon - 'bušklna (del. -l, m dv), kslon - d'ra:kslnax (Mmn)

+ no + čknm - 'mičknomu (Ded)

$\mathbf{N}+\mathbf{N}+\mathbf{Z}+\mathbf{N}$

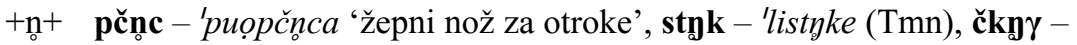
'mičkgra (Red)

$\mathbf{Z}+\mathbf{N}+\mathbf{Z}+\mathbf{N}+\mathbf{N}$

$+1+\mathbf{m p l c c ̌ k}-k^{\prime}$ romplčcki 'krempeljčki'

\section{$4 \quad$ Sklopi na meji dveh besednih enot}

$\mathrm{Na}$ začetku besede dobimo v govorni verigi v položaju za samoglasnikom še naslednje soglasniške sklope z $\underset{\sim}{u}$ (oz.j) na prvem mestu.

\subsection{1 $Z+Z$}

jm-j'mi:l 'imeli', j'mie 'ime'

\subsubsection{Z + N}

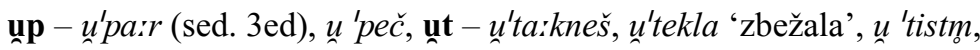

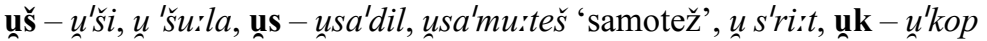

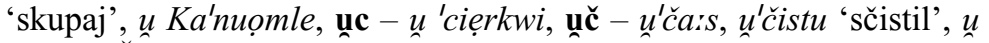
'čel = v Čelu T, unx - úx'xa:t 'phati', u'xiš

4.2.1 $\mathrm{Z}+\mathrm{N}+\mathrm{Z}$

upl - upli'ta:l 'vpletali', uppr - uprey'nila 'prepognila', up'rięl, uيntr unt'rejene = utrjene, unsm - us'mil, unsj - uns'ja:l, unsr - uns'ra:n, uيšl - uns šlla, unšr - uñ'ra:ufane, unkr - unkre'pa: (del. -l, ž ed), unk'ra:st

\subsection{2 $\mathrm{Z}+\mathrm{N}+\mathrm{N}$}

ust - us'ta:jet, unsc - uns'ca:n 


\section{3 $\quad \mathrm{Z}+\mathrm{N}+\mathrm{N}+\mathrm{Z}$}

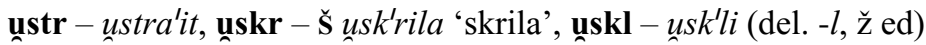

$\mathrm{V}$ gradivu je bilo mogoče najti največ petdelne medbesedne soglasniške sklope - štər'na:jst x'li:bau 'hlebcev', 'ku:jst spad'raise 'tako preraste', vendar so ti redkejši, tri- ali štiridelni sklopi pa so v govorjenju običajni: k'rap s'kuxam, 'kar s'puotje, 'bel z'zu:dne, je za'čiẹ pla'čowat, 'sinu al x'čiẹr; 'ka:r se 'jest s'po:unem, 'tu:lk s'ta:ra, sa na 'pust ple'sa:l, 'kajt s'la:bya 'veliko' itd. Zveze treh zvočnikov so pogostejše kot sredi besede: sma nar'dil m'lince, p'recej m'li:ka, p'rọu m'la:de, 'bel m'ras, jứla 'je bila', kor ư're 'ko vre'.

\section{Navedenke}

Baudouin de Courtenay 1884 = Jan Baudouin de Courtenay, Der Dialekt von Cirkno (Kirchheim), Archiv für slavische Philologie 7 (1884), 386-404, 575-590.

Bric-Makuc 1982 = Slavica Bric-Makuc, Govor kraja Cerkno (diplomska naloga), Ljubljana, 1982. (Tipkopis.)

Brozović 2006 = Dalibor Brozović, Dentali ispred afrikatâ: gube se ili izgovaraju, v: Dalibor Brozović, Neka bitna pitanja hrvatskoga jezičnog standarda, Zagreb: Školska knjiga, 2006, 65-82.

Fonološki opisi 1981 = Fonološki opisi srpskohrvatskih/hrvatskosrpskih, slovenačkih i makedonskih govora obuhvaćenih opšteslovenskim lingvističkim atlasom, ur. Pavle Ivić, Sarajevo: Akademija nauka i umjetnosti Bosne i Hercegovine, 1981 (Posebna izdanja LV, Odjeljenje društvenih nauka 9).

Jurgec 2003 = Peter Jurgec, Drago Unuk, Zlog v slovenskem jeziku (Ljubljana 2003), Jezikoslovni zapiski 9, št. 2, Ljubljana: ZRC SAZU, 2003, 153-159.

Kenda-Jež 1998 = Karmen Kenda-Jež, Cerkljansko narečje v luči raziskav Jana Baudouina de Courtenayja, v: Vatroslav Oblak: Mednarodni simpozij Obdobja, Ljubljana, 12. in 13. december 1996, ur. Alenka Šivic-Dular, Ljubljana: Center za slovenščino kot drugi/tuji jezik pri Oddelku za slovanske jezike in književnosti Filozofske fakultete, 1998 (Obdobja 17), 145-152.

Kenda-Jež 1999 = Karmen Kenda-Jež, Fonološki opis govora kraja Cerkno (OLA 6, SLA 166), Jezikoslovni zapiski 5, Ljubljana: ZRC SAZU, 1999, $207-234$. Logar 1993 = Tine Logar, Slovenska narečja: Besedila, Ljubljana: Mladinska knjiga, ${ }^{2} 1993$ (Cicero).

Logar 1996a = Tine Logar, Konzonantni sistemi v slovenskih narečjih, v: Tine Logar, Dialektološke in jezikovnozgodovinske razprave, Ljubljana: ZRC SAZU - Inštitut za slovenski jezik Frana Ramovša, 30-35. [Prva objava leta 1978.]

Logar 1996b = Tine Logar, Članki za Enciklopedijo Slovenije: Rovtarska narečja, v: Tine Logar, Dialektološke in jezikovnozgodovinske razprave, Ljubljana: ZRC SAZU - Inštitut za slovenski jezik Frana Ramovša, 407-412.

Orožen 1990 = Martina Orožen, Konzonantski sklopi v slovenskem jeziku, Zbornik Matice srpske za filologiju i lingvistiku (Novi Sad) 33 (1990), str. 345-350. 
Pavšič 1960 = Tomaž Pavšič, Opis cerkljanskega dialekta vasi Otalež (Diplomska naloga (A) za seminar prof. Logarja), 1960. (Tipkopis.)

Ramovš 1935 = Fran Ramovš, Historična gramatika slovenskega jezika VII: Dialekti, Ljubljana: Učiteljska tiskarna, 1935 (Znanstveno društvo za humanistične vede v Ljubljani, Dela I).

Ramovš 1936 = Fran Ramovš, Kratka zgodovina slovenskega jezika I, Ljubljana: Akademska založba, 1936 (Akademska biblioteka 3).

Rigler 1966 = Jakob Rigler, Cerkno (OLA 6): zapis za OLA, 1966. (Rokopis v dialektološki sekciji Inštituta za slovenski jezik Frana Ramovša ZRC SAZU v Ljubljani.)

Rigler 1981 = Jakob Rigler, Cerkno (OLA 6), v: Fonološki opisi 1981, str. 67-78.

SP 1962 = Slovenski pravopis, Ljubljana: SAZU - DZS, 1962.

Srebot-Rejec 1975a = Tatjana Srebot-Rejec, Soglasniški sklopi v slovenščini in kontrastivna analiza angleških in slovenskih soglasniških sklopov: Magistrska naloga, Ljubljana, 1975. (Tipkopis.)

Srebot-Rejec 1975b = Tatjana Srebot-Rejec, Začetni in končni soglasniški sklopi v slovenskem knjižnem jeziku, Slavistična revija 23 (1975), str. 289-320.

SSKJ = Slovar slovenskega knjižnega jezika 1-5, Ljubljana: SAZU - DZS, 19701991.

Toporišič 1978 = Jože Toporišič, Soglasniški sklopi slovenskega knjižnega jezika, v: Jože Toporišič, Glasovna in naglasna podoba slovenskega jezika, Maribor: Založba Obzorja, 1978, 30-42. [Prva objava leta 1959.]

Toporišič 1992 = Jože Toporišič, Enciklopedija slovenskega jezika, Ljubljana: Cankarjeva založba, 1992.

Unuk 2003 = Drago Unuk, Zlog v slovenskem jeziku, Ljubljana: Rokus - Slavistično društvo Slovenije, 2003 (Slavistična knjižnica 7).

Zdovc 1972 = Paul Zdovc, Die Mundart des südöstliches Jauntales in Kärnten: Lautlehre und Akzent der Mundart der »Poljanci«, Wien: Österreichische Akademie der Wissenschaften, 1972 (Schriften der Balkankomission, Linguistische Abteilung 20). 


\section{Consonant Clusters in the Cerkno Dialect}

\section{Summary}

Clusters of up to four consonants can appear in all positions in the central Cerkno dialect. Across word boundaries it is possible to find up to five-consonant clusters, but these are rare (e.g., 'kuijst spad'raise, Standard Sln. tako preraste 'that is how it overgrows'), whereas three- or four-consonant clusters are typical in spoken language. The number of possible units in a cluster is therefore somewhat smaller than in the standard language (five in initial position, four in final and medial position, and up to eight at word boundaries), mostly due to the consonant sequences $n+j, l+j\left(l, n^{\prime}\right)$. In addition to strong vowel reduction, the different number and distribution of individual consonant clusters in the standard language versus the Cerkno dialect is partially influenced by the different phonological structure of borrowed words and the development of the dialect's phonemic inventory; for example, the assimilation (-)wu: $>u$ : ('du:jčk, Standard Sln. dvojček 'twin'; 'tu:j, Standard Sln. tvoj 'your'), which reduces the number of consonant clusters, or the development of post-tonic wi $(i<i, \breve{e})$ into $j$, which greatly increases the frequency of $j+$ obstruent. In contrast to the standard language, in this dialect it is also possible to have clusters containing two identical consonants in both initial and final positions (e.g., s'sirkane, Standard Sln. sesekane 'chopped up' [nom. f. pl. adj.]; z'zidal, Standard Sln. sezidali 'built' [m. pl. 1-ptcp.]; xatt, Standard Sln. hoditi 'to walk'). With regard to distribution, two-obstruent clusters in final position differ most from their counterparts in the standard language, although the number of clusters is almost the same in both. The numerical ratio (29:13) between such clusters in the dialects of Cerkno and the Jaun Valley (Germ. Jauntal, Sln. Podjuna; documented by Pavel Zdovc) indicates that this could serve as one of the measurable indicators of the degree of vowel reduction in Slovenian dialects. 